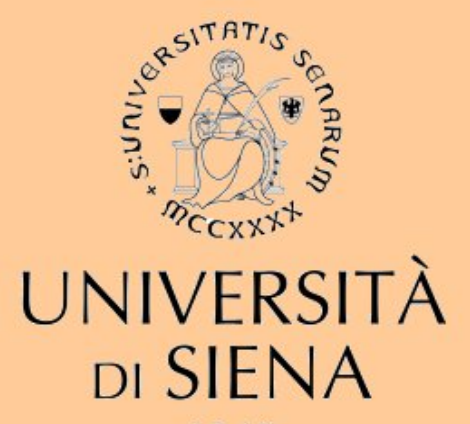

1240

QUADERNI DEL DIPARTIMENTO

DI ECONOMIA POLITICA E STATISTICA

Alesia Kalbaska

From Sovereigns to Banks: Evidence on

Cross-border Contagion (2006-2011)

n. 680 - Agosto 2013

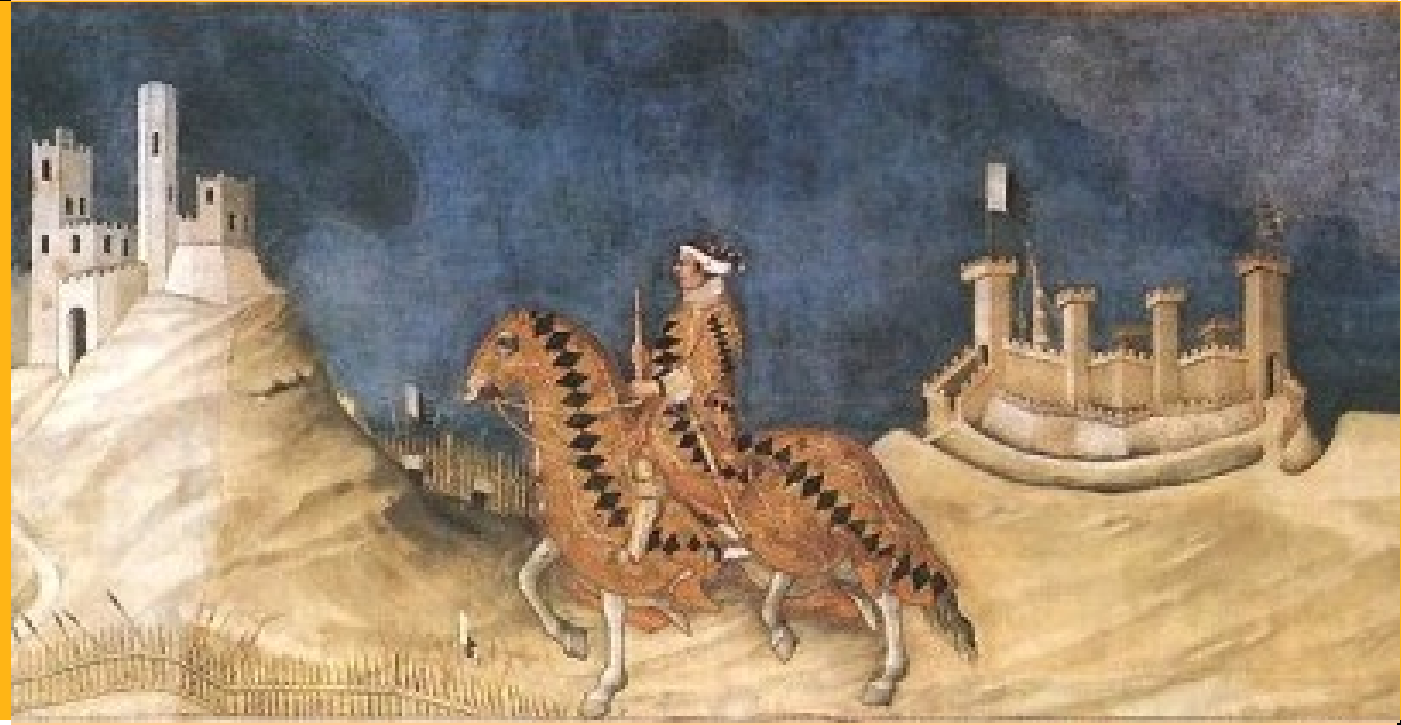




\title{
From Sovereigns to Banks: Evidence on Cross-border Contagion (2006-2011) ${ }^{1}$
}

\author{
Alesia Kalbaska \\ University of Siena, Department of Economics and Statistics, 7 S. Francesco Sq, Siena \\ 53100 , Italy \\ Email address: alesia.kalbaska@gmail.com
}

\begin{abstract}
This paper analyzes the evolution of the banking system sensitivity to cross-border contagion over the period of 2006-2011. The study is performed on the basis of the BIS data on crossborder exposures and the Bankscope data on Tier 1 capital of 20 banking systems (Australia, Austria, Belgium, Canada, Finland, France, Germany, Greece, India, Ireland, Italy, Japan, the Netherlands, Portugal, Spain, Sweden, Switzerland, Turkey, the UK and the US). Since the European sovereign debt crisis took a decisive turn at the end of 2009, markets started looking at its main protagonists - so called PIIGS (Portugal, Ireland, Italy, Greece and Spain) - with a lot of anxiety. However, unexpectedly, the analysis of the data shows that a single failure among PIIGS could be absorbed by the network in 2011. Nevertheless, multiple initial failures (especially combinations including Italy and/or Spain) could be more dangerous. The simulation results reveal that the resilience of banking systems to contagion risks tends to improve over the years. The most systemically important countries are those of the US, the UK, France and Germany. Besides, a shock to the US is capable of destroying the UK banking system already in the first round, whereas the UK would not lead to the failure of the US banking system even after all rounds of contagion. The results also show that the banking systems of the US, Turkey and Finland are completely immune to contagion effects. At the same time, there exist considerable risks for Switzerland and Ireland as their banking systems default also with high recovery rates.
\end{abstract}

JEL classification: F34, F37, G01, G15, G21

Keywords: contagion, Furfine algorithm, stress testing, PIIGS

\footnotetext{
${ }^{1}$ The author is grateful to Alessandro Vercelli and Giampaolo Gabbi for their helpful comments and suggestions. The author is also thankful to the participants of the 2nd PhD Student Conference in International Macroeconomics and Financial Econometrics (especially to the discussants of this paper Olena Havrylchyk and Jean Yves Gnabo) held at the University of Paris Quest - Nanterre La Défense in Paris in March 2013, Workshop on Network Approaches for Interbank Markets organized by the University Jaume I of Castellón, the University of Kiel and the Kiel Institute for the World Economy in Benicassim in May 2013 and VIII Seminar on Risk, Financial Stability and Banking organized by the Central Bank of Brazil in São Paulo in August 2013.
} 


\section{Introduction}

The US subprime mortgage crisis and the ensuing European sovereign debt crisis have heightened the need for policymakers and regulators all over the world to look beyond national borders to monitor systemic risk. As pointed out by Allen and Babus (2008), network theory can assist in this matter as it allows to reveal dependencies between financial institutions and assess the danger of a shock spreading through the whole system via direct financial linkages.

A considerable amount of literature has been published on systemic risk and contagion in financial networks. The theoretical underpinning is provided, among others, by Allen and Gale (2000), Iori et al. (2006), Nier et al. (2007), Babus (2009), Gai and Kapadia (2010), Martinez-Jaramillo et al. (2010), Acharya et al. (2010), Bolton and Jeanne (2011).

A large part of the theoretical contribution focuses on the study of the effect of various parameters and network structures on the resilience of the network to contagion. Thus, Allen and Gale (2000) model contagion in the network formed by four banks. The authors suggest that the likelihood of the propagation of financial distress between network players is mainly determined by the nature of their interconnectedness. Thus, complete network structures, where all entities are connected to each other, are more resilient to contagion as each entity bears a small share of the shock. By contrast, in incomplete networks the losses of a distressed entity are distributed between fewer connected players, which increases the impact of the shock on each player. Iori et al. (2006) discuss a dual role of the interbank market: as an insurer against liquidity shortages experienced by individual banks and as a source of contagion spreading from a distressed bank to other banks. They show that in the network with homogeneous banks the interbank market performs mainly the role of a stabilizer of the system; whereas networks with heterogeneous banks are more prone to knock-on defaults.

Nier et al. (2007) apply network theory to capture the generic relationship between the level of systemic risk in the banking system and its key characteristics such as the size of exposures, capital buffers, degree of connectivity and degree of concentration. The authors conclude that the higher interbank exposures and the lower banks' capital buffers, the more susceptible to contagion effects is the banking system. Besides, more concentrated banking systems are exposed to larger systemic risks. Another important finding is that the degree of connectivity has a non-monotonic effect on 
the resilience of a banking system to contagion. Thus, at first a small increase in connectivity causes large contagion effects; however, the resilience to contagion improves when connectivity reaches a certain point. Similarly, Babus (2009) shows that when banks reach a certain connectivity threshold, they are capable of forming networks resilient to contagion risks. Gai and Kapadia (2010) examine how the likelihood of contagion and its potential impact vary with aggregate and idiosyncratic shocks, changes in network structure and liquidity of the asset market. The authors suggest that the financial market can be characterized by a robust-yet-fragile nature, i.e., contagion is rather an unlikely event, but can have devastating effects once it occurs.

There are also works that examine the implications of sovereign debt crises for the banking sector. For instance, Bolton and Jeanne (2011) propose a sovereign debt model, where, due to financial integration, banks of one country use the government debt of another country as collateral in the interbank market. In an attempt to minimize their costs resulting from an individual country's default, banks diversify their portfolios but inevitably expose themselves to a higher systemic risk and contagion. The authors show that in financially integrated economies, without fiscal integration, the government debt is supplied inefficiently. Thus, the safest governments supply too low amounts of the safe debt, whereas the riskiest economies issue too much of the risky debt. According to the authors, the introduction of fiscal integration between countries could eliminate these inefficiencies.

Furthermore, some works are devoted to the measurement of systemic risk. ${ }^{2}$ Thus, Martinez-Jaramillo et al. (2010) estimate the distribution of losses for the banking system and distinguish between initial losses and contagion losses. Besides, the authors propose a measure of fragility for the banking system and calculate it for different years in order to track the vulnerability of the financial system over time. Acharya et al. (2010) measure the contribution of each financial institution to systemic risk as its systemic expected shortfall (SES), i.e., its propensity to be undercapitalized when the system as a whole is undercapitalized. According to the authors, the higher the level of institution's leverage and the higher the expected losses during a crisis, the larger is its SES. The authors argue that imposing a tax based on institution's SES can reduce its contribution to systemic risk. Furthermore, they show empirically that SES appears to be helpful in the prediction of the risks emerging in the system during the recent global financial crisis.

\footnotetext{
${ }^{2}$ Bisias et al. (2012) provide a survey of various quantitative measures of systemic risk to be used in economics and finance.
} 
Besides numerous theoretical contributions on systemic risk and financial contagion, a large body of empirical literature has emerged on the topic. In some empirical studies researchers compute network measures and track the evolution of network properties over time. Thus, von Peter (2007) shows how network measures can be used to identify the most important banking centers in the international banking network. Likewise, Hattori and Suda (2007) compute various network measures and find that the network of cross-border bank exposures became more interconnected over time. Garratt et al. (2011) apply a network clustering technique to estimate how the interconnectedness of 21 international banking groups affects the spread of systemic risk in the network in 1985-2009. The authors find that the contagious capacity of the international banking network was increasing during that period and peaked at the time of the Lehman Brothers collapse. In a similar vein, Minoiu and Reyes (2011) study the evolution of the global banking network of 184 countries over the period of 1978-2009 and document that the network was relatively unstable. Besides, the authors reveal structural breaks in the network indicators and reduced connectivity between network players during and after systemic crises.

In recent years, there has been an increasing amount of literature that focused on monitoring systemic risk within banking systems of individual countries. Examples can be found in Boss et al. (2003) for Austria, Wells (2004) for the UK, Müller (2006) for Switzerland, van Lelyveld and Liedorp (2006) for the Netherlands, Degryse and Nguyen (2007) for Belgium, Furfine (2009) for the US, Toivanen (2009) for Finland, Rø rdam and Bech (2009) for Denmark, Canedo and Jaramillo (2009) for Mexico, Krznar (2009) for Croatia, Mistrulli (2011) for Italy, Fungáčová and Jakubík (2012) for Russia, etc. Most papers in this strand have access to the data on interbank exposures only on the aggregate basis. In order to know the actual structure of bilateral exposures, the authors apply statistical methods (e.g., the maximum entropy technique) assuming that bank lending is spread as evenly as possible. The majority of papers finds that contagion appears to be a possible but rather an unlikely event. Upper (2011) provides a critical overview of this literature and argues that it needs to incorporate behavioral foundations in order to be more suitable for policy making.

Several attempts have been also undertaken to analyze cross-border linkages. Thus, Cihák et al. (2011) and Schoenmaker and Wagner (2011) study costs and benefits of cross-border banking and argue that after a certain value gains from the increase in cross-border linkages diminish and fragility increases. International Monetary Fund (2011) distinguishes the main determinants of cross-border linkages and finds empir- 
ically that geographical, historical and cultural factors account for their magnitude the most. Espinosa-Vega and Solé (2010) and Chan-Lau (2010) illustrate how financial surveillance across borders can be analyzed with network methods. The authors consider not only credit but also funding shocks and their joint realization at a particular point in time. Similarly, Degryse et al. (2010) study cross-border contagion from triggering countries to banking systems of recipient countries in a multi-period context (1999-2006).

So far, however, there has been relatively little discussion on the potential spread of turbulence in sovereigns in the European sovereign debt crisis to banking systems of other countries through banks' foreign exposures to sovereign debt. Fears that European banks have too extensive exposure to sovereign bonds issued by fiscally weak PIIGS raised a lot of worries among investors that a sovereign default could wipe out banks' capital reserves and make unavoidable other bailouts. Indeed, in 2011 financial markets witnessed the spread of tensions not only to other sovereigns but also to banks exposed to the sovereign debt of PIIGS. CGFS (2011) discusses the main channels through which sovereign tensions propagate to the banking sector. The authors stress that banks need to build up sufficient capital buffers in order to reduce the risk of domestic and cross-border contagion. Blundell-Wignall and Slovik (2010) carry out a study in which they conduct stress tests for 18 EU member countries. The authors consider small trading book exposures of 91 European banks to sovereign debt of other countries and find that most banks appear to be resilient.

In an attempt of contributing to this field, we track changes in the banking system sensitivity to cross-border contagion over the period of 2006-2011. Our study differs in several respects. Firstly, rather than using the Bank for International Settlements (BIS) data on an immediate borrower basis, we use a dataset on an ultimate risk basis. It provides a more accurate picture of banks' true exposures as they are adjusted for risk mitigants such as guarantees and collateral. Secondly, while most of the studies attempt to capture contagion effects only for one-period snapshot, we take into account the time dimension as suggested by Cihák (2007). We employ a six-year horizon (2006-2011) to investigate how the resilience of banking systems to contagion risk evolves over time.

In this study we define contagion as a situation in which losses from claims to a defaulting country are capable of causing a failure of banking systems of other countries. The definition of contagion is maintained mechanic to allow an easy assessment of both direct and knock-on effects in the network. 
Firstly, we present a set of stylized facts on cross-border activities of eight countries (PIIGS, France, Germany and the UK). The data analysis shows that a single failure among PIIGS is not sufficient to trigger the default of a banking system of another country. However, multiple failures among PIIGS (especially combinations including Italy and/or Spain) could be more dangerous.

Secondly, in order to account for all potential linkages, we use a simple model to simulate contagion and amplification mechanisms affecting banks' capital levels for an extended sample of 20 countries (Australia, Austria, Belgium, Canada, Finland, France, Germany, Greece, India, Ireland, Italy, Japan, the Netherlands, Portugal, Spain, Sweden, Switzerland, Turkey, the UK and the US). To the best of our knowledge, this is the first study that covers such a wide range of countries to examine possibilities of contagion from sovereigns to banks in the current crisis. The simulation results show that the resilience to contagion tends to improve over the years. The US, the UK, France and Germany are the most important systemic players. Besides, a shock to the US would transmit to the UK banking system already in the first round, whereas the UK would not affect the US banks even after all rounds of contagion. The banking systems of the US, Turkey and Finland seem to be completely immune to contagion effects; whereas Switzerland and Ireland appear the most vulnerable players as their banking systems default also with high recovery rates.

The rest of the paper is organized as follows. Section 2 analyzes the BIS and Bankscope data to draw some preliminary results. Section 3 describes the estimation methodology - the Furfine algorithm. Section 4 discusses the simulation results. The last section concludes.

\section{BIS and Bankscope Data Analysis}

The data on consolidated foreign exposures were taken from the BIS consolidated banking statistics that report lending by the headquartered banks and all their branches around the world on a consolidated basis (i.e. net of interoffice account). ${ }^{3}$ The data inform about the exposures of the national banking system in one country to all sectors (bank, non-bank and public sector) in another country. Mcguire and Tarashev (2008) and Weistroffer and Möbert (2010) show how to explore the BIS data most

\footnotetext{
${ }^{3}$ BIS also provides locational banking statistics that report lending by all banks located in a given country on a gross (unconsolidated) basis. However, it is impossible to measure national banking systems' exposure to individual countries on the basis of these statistics because of the residency principal of their collection.
} 
effectively in order to monitor banking sector risks resulting from its cross-border exposure.

In this study foreign exposures are used on an ultimate risk basis (i.e., contractual lending net of guarantees, collateral and other credit risk transfers). ${ }^{4}$ These data allocate claims to the country of ultimate risk (where the guarantor of a claim resides) and may differ substantially from contractual lending (reported on an immediate risk basis) as a result of risk mitigation.

In the face of the European sovereign debt crisis, our primary interest lies in the study of cross-border contagion in Europe. For this reason, the preliminary data analysis is done for the main protagonists of the Eurozone debt crisis - Portugal, Ireland, Italy, Greece, Spain (PIIGS) and France, Germany and the UK (core countries) that have a high exposure to PIIGS. The data on the ultimate risk basis are available since March 2005 for all the countries apart from Ireland; therefore, the analysis covers the period of 2006-2011.

Figure 1 demonstrates that the exposure of core banking systems to PIIGS has been growing since March 2006 for two consecutive years. After that, especially following the collapse of Lehman Brothers in September 2008, cross-border lending started decreasing. At the beginning of 2010, for the first time since the Lehman Brothers collapse, cross-border lending by banks rose again. Nevertheless, in the second quarter of 2010 it dropped substantially implying the outflow of capital from European economies toward more stable regions.

Figure 1 also shows that since 2008 PIIGS have been owing more to French banks than to German and British banks. Interestingly, until December 2007 German banks were leading in cross-border lending to PIIGS. However, since June 2008 their flows to PIIGS started contracting more than those of French and British banks.

Figure 2 reveals to which extent sovereigns and banking systems of other nations are connected. It shows how much a banking sector in a particular country is owed by each of PIIGS, France, Germany and the UK for December 2006-2011. ${ }^{5}$

\footnotetext{
${ }^{4}$ German banks' foreign claims vis-à-vis developed countries are available only on an immediate borrower basis.

${ }^{5}$ These dynamics could have been affected by cross-border mergers and acquisitions activities. Thus, von Peter et al. (2006) point out that mergers contribute to the increase in local claims that refer to claims of reporting banks' foreign offices on residents of the country where these foreign offices are located (N.B. local claims in local and foreign currencies along with cross-border claims form
} 


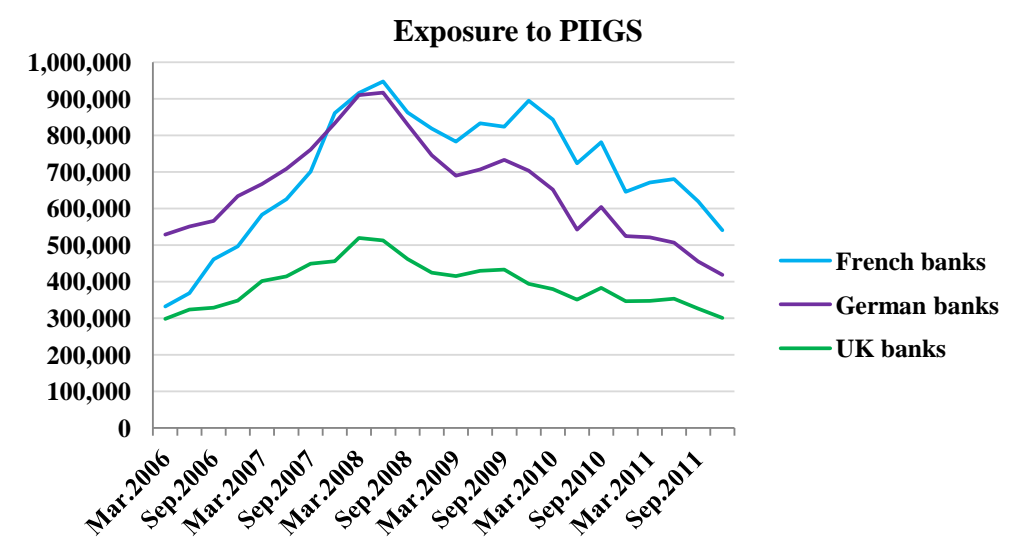

Figure 1: Foreign exposure of core banking sector to PIIGS in total (USD millions) Source: own elaboration based on the BIS data.

Thus, the banking systems of three of PIIGS - Greece, Ireland and Spain - are most exposed to the UK debt, even though their exposure differs considerably in absolute terms. ${ }^{6}$ Interestingly, Greek banks lend more funds to core countries than to other PIIGS. In contrast, Irish banks, apart from being exposed to core (mostly to the UK), also hold high cross-border claims on Italy and Spain. Regarding Spanish banks' relationship with other PIIGS, they are most exposed to Portugal and least to Greece. Portuguese banks are in return highly exposed to the Spanish debt, whereas Italian banks hold the highest claims on Germany.

Figure 2 also presents the structure of core banking systems' exposure. Thus, French banks have the highest claims on Italy but are also extensively exposed to the UK, Germany and Spain. At the same time, German banks are most of all owed by the UK. The German banking sector also holds high claims on France, Spain, Italy and Ireland. As for the UK, its banks are highly exposed to other core countries (more to France than to Germany). Regarding the exposure of the UK banking system to PIIGS, it has a higher exposure to Ireland than to Spain and Italy. In other words, the inability of Ireland to pay its debt would incur higher losses for the UK banks than the non-payment of debt by other PIIGS.

The data on cross-border exposures allow to see how many losses would be incurred by banking systems in case of the non-payment of debt by their counterparties. However,

foreign claims of a banking system). For example, in 2005 Italian UniCredit SpA (then UniCredito Italiano) took over all of Germany's HVB Group. In 2006 French BNP Paribas bought Italian Banca Nazionale del Lavoro, whereas French Crédit Agricole gained about $72 \%$ of Greek Emporiki Bank. In 2008 Spanish Santander bought British mortgage bank Alliance and Leicester (see Chin (2013)).

${ }^{6}$ The exposure of Spanish banks to the UK is more than 30 times higher than that of Greek banks. 

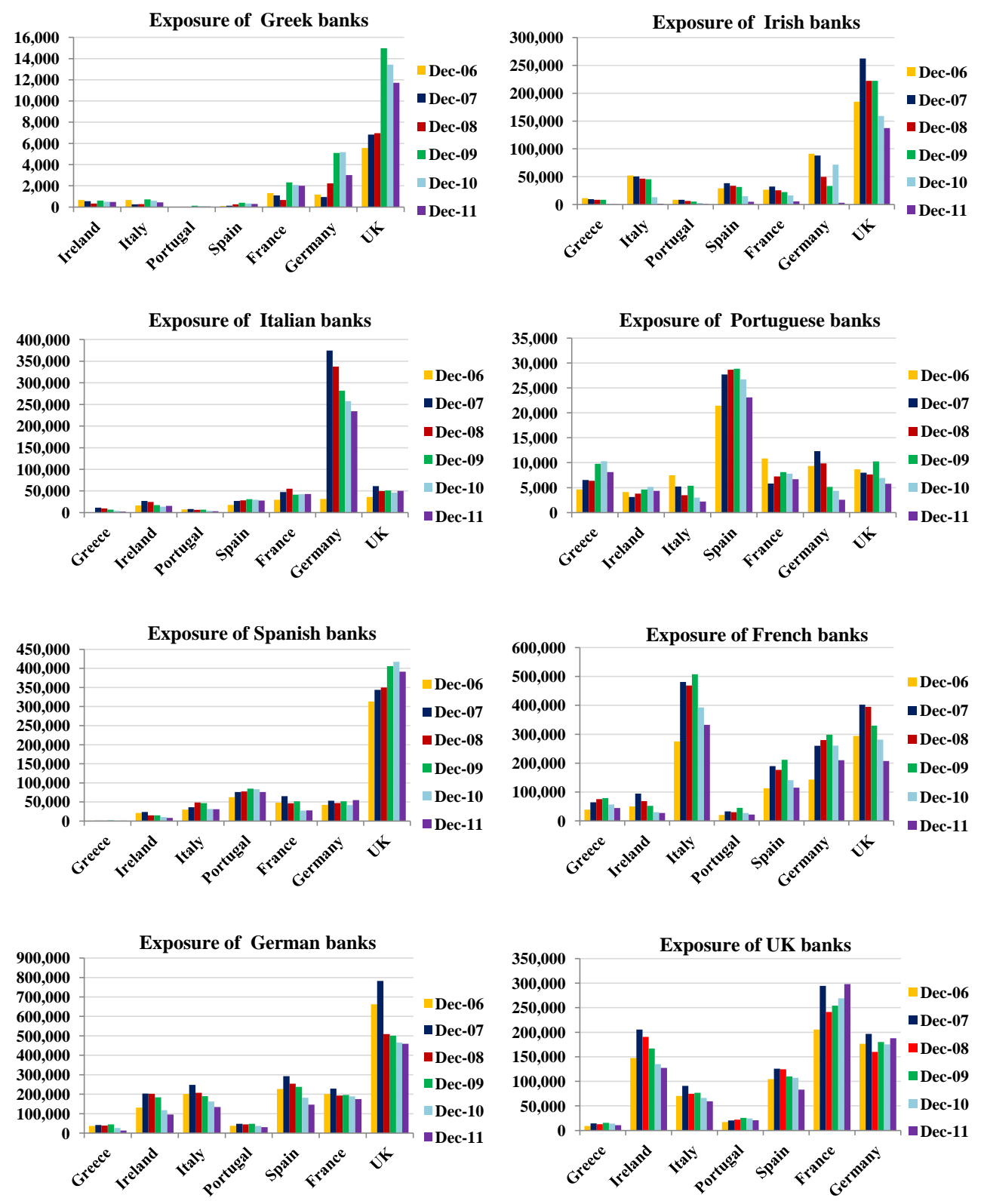

Figure 2: Banking sector foreign exposure to PIIGS, France, Germany and the UK (USD millions)

Source: own elaboration based on the BIS data. 
in order to determine to which extent these losses can be absorbed, it is important to consider capital levels of the exposed banking systems.

The data on Tier 1 capital were collected from Bankscope and are presented in Table 4 in the Appendix. In order to calculate the aggregate value, we considered the sum of Tier 1 capital of all financial institutions ${ }^{7}$ in the country (excluding the Central bank) at the end of each year.

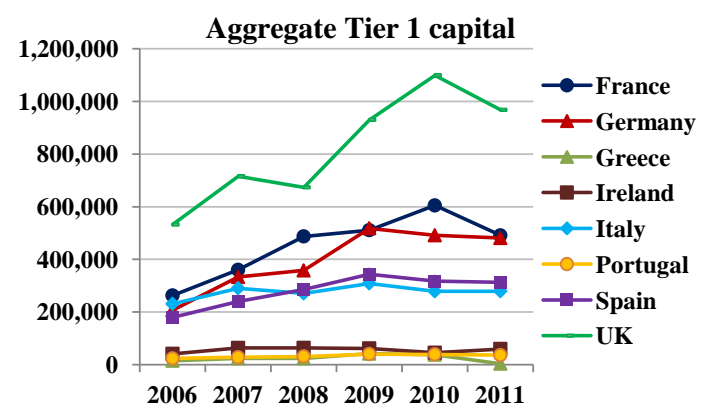

Figure 3: Tier 1 capital of banking systems of PIIGS, France, Germany and the UK (USD millions.)

Source: own elaboration based on the Bankscope data.

Figure 3 displays the dynamics of the aggregate Tier 1 capital of banking systems of PIIGS and core. Core countries maintain considerably higher capital levels (with the UK in the lead) than PIIGS. Regarding PIIGS, Italy and Spain are capitalized better than Ireland, Portugal and Greece, which is understandable given a bigger size of their economies and hence larger banking sectors. The figure also shows that the levels of Tier 1 capital have been changing over the years and in absolute terms increased more for core than for PIIGS. ${ }^{8}$ This fact could be explained by a growing uncertainty over the future of PIIGS, which increased the necessity of the core to recapitalize its banks.

Table 5 in the Appendix illustrates the ratio of foreign claims to Tier 1 capital of PIIGS and core. Calculations are done for both total foreign claims (liabilities of all

\footnotetext{
${ }^{7}$ For simplicity these financial institutions are later referred to as banks and include commercial banks, savings banks, cooperative banks, real estate and mortgage banks, investment banks, Islamic banks, specialized governmental credit institutions, bank holdings and holding companies, multilateral governmental banks, micro-financing institutions, securities firms, private banking/asset management companies, investment and trust corporations, finance companies, clearing and custody institutions, group finance companies.

${ }^{8}$ Banking systems of Greece, France and the UK are characterized by lower capital levels in 2011 compared to 2010. It could suggest that either there occurred the actual reduction of their aggregate Tier 1 capital or that not all financial institutions of these banking systems provided their information for 2011 at the time of download of the Bankscope data.
} 
counterparties) and the largest claim (counterparty with the largest liability) of each banking system. Figure 4 emerges from this table and shows the ratio averaged over time. The red line shows the situation when the ratio is equal to one (foreign claims are equal to Tier 1 capital). Thus, the ratio below this line reflects total immunity of the banking system of a country to external shocks and cross-border contagion. In contrast, the ratio above the line means that there are insufficient funds in a country's banking system to absorb the losses from the non-payment of its total (the largest) foreign claims.

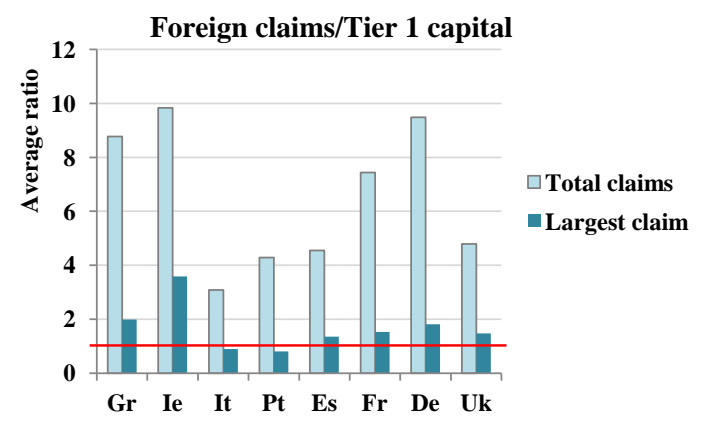

Figure 4: Average ratio of foreign claims to Tier 1 capital of banking institutions Note: country abbreviations: $\mathrm{Gr}=$ Greece, $\mathrm{Ie}=\mathrm{Ireland}$, It $=\mathrm{Italy}, \mathrm{Pt}=$ Portugal, Es $=$ Spain, $\mathrm{Fr}=$ France, $\mathrm{De}=$ Germany, Uk=United Kingdom.

Source: own calculations based on Table 5 in the Appendix.

On the whole, none of the banking systems is completely immune to cross-border contagion since for all of them total foreign claims exceed the available funds of their banking systems. Regarding PIIGS, the ratio is especially high for Irish banks (foreign claims are almost ten times higher than the aggregate Tier 1 capital), whereas the German banking system has the highest ratio among core countries. As for the ratio with the largest claim, Italian and Portuguese banks have enough funds to cover the losses from the non-payment of even their largest claim. On the contrary, Greek, Spanish, French, German, the UK and especially Irish banks would not be able to absorb the shock in case of default of their largest debtor. ${ }^{9}$

Figure 5 presents the ratio of claims to Tier 1 capital given the initial default of up to four PIIGS in 2011. As before the red lines correspond to the case when ratios are equal to one, i.e., claims to up to four defaulting PIIGS are equal to Tier 1 capital of the banking systems exposed to them.

\footnotetext{
${ }^{9}$ In most of the years, the largest debtor of Greece is Turkey; of Italy is Germany; of Portugal is Spain; of Ireland and Spain is the UK; of France, Germany and the UK is the US.
} 


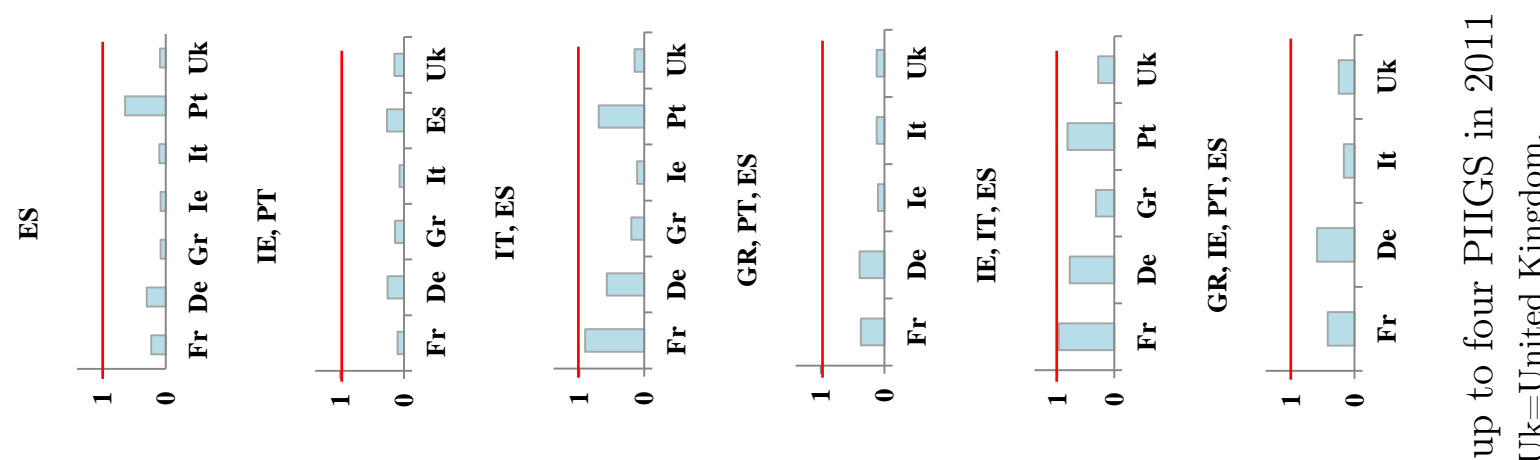

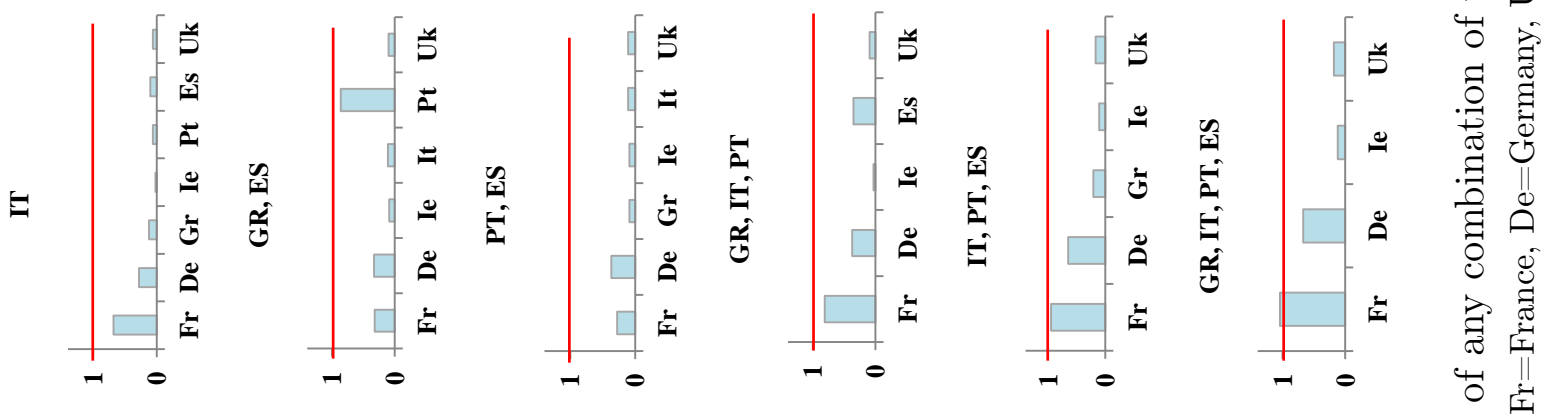

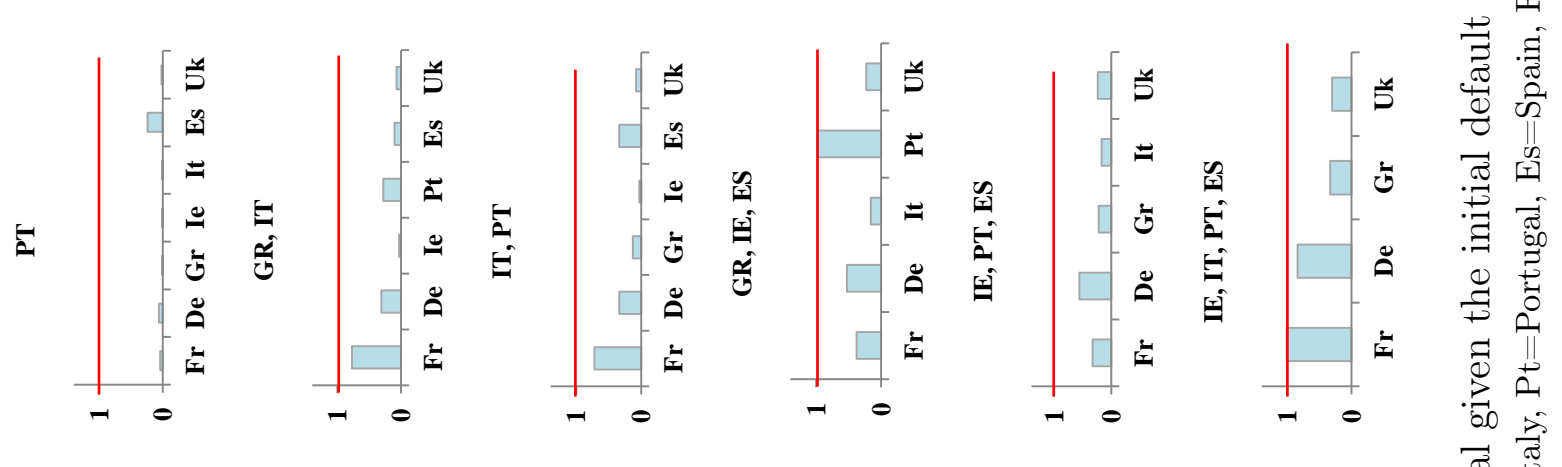

का

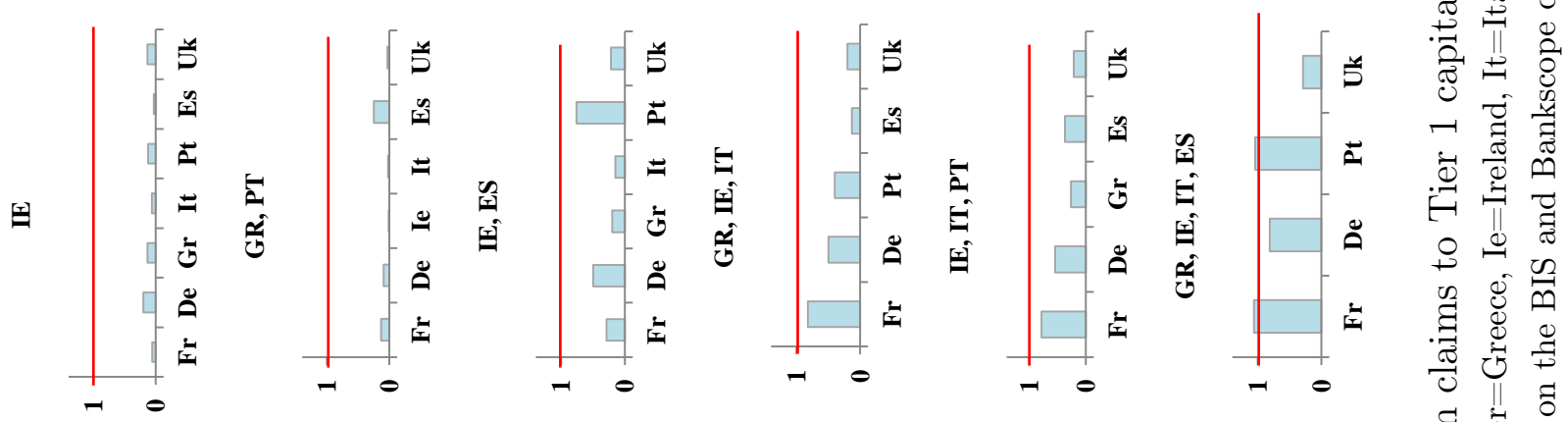

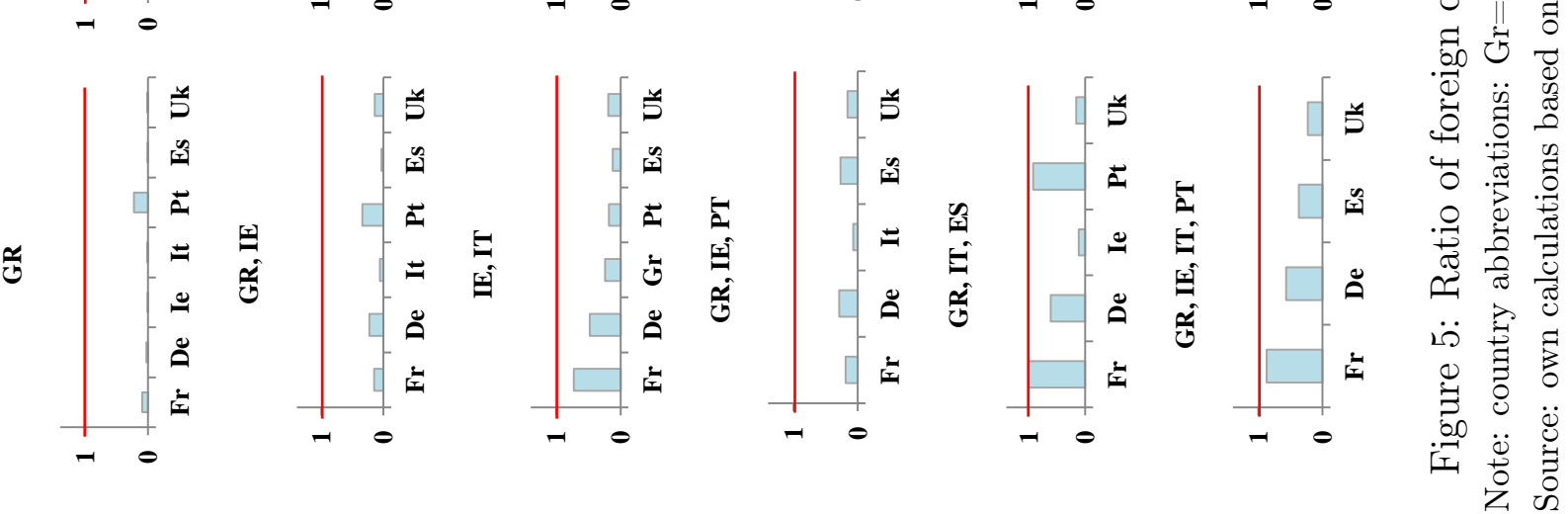



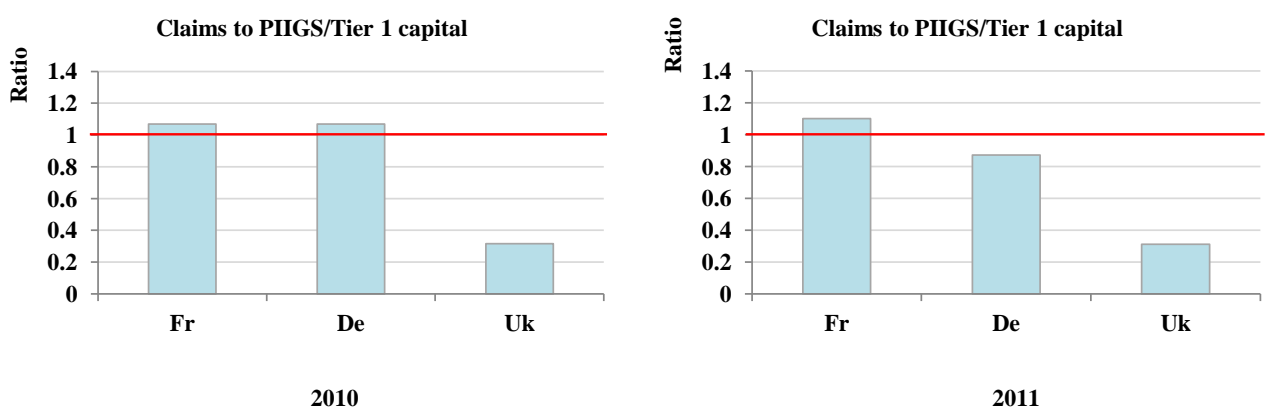

Figure 6: Ratio of foreign claims to all PIIGS to Tier 1 capital of France, Germany and the UK

Note: country abbreviations: $\mathrm{Fr}=$ France, $\mathrm{De}=$ Germany, Uk=United Kingdom.

Source: own calculations based on the BIS and Bankscope data.

The figure shows that a default of one of PIIGS, even Spain and Italy, results in ratios lower than one, which means that such a shock would be fully absorbed by all banking systems of the countries under analysis. At the same time, a default of some combinations of two PIIGS results in higher ratios, however, they still remain at levels below the red lines. It is not surprising that the ratios are higher in case of default of the pairs with Spain and/or Italy. For instance, a simultaneous default of Greece and Spain would hardly be sustained by Portuguese banks, whereas a default of Italy and Spain would put on edge the French banking system.

As to the combined default of three PIIGS, in several cases the ratio is very close or equal to one. French and Portuguese banks again appear to be the most vulnerable. For instance, losses from a simultaneous default of Greece, Ireland and Spain would wipe out $98 \%$ of the Portuguese capital. Similarly, a default of Greece, Italy and Spain would require all the capital of French banks and $92 \%$ of the capital of Portuguese banks to cover their losses.

Regarding a simultaneous default of four PIIGS, the ratio appears above the red line in several cases. It means that there could be cross-border contagion to some banking systems already in the first round. For instance, the combination of defaulting Greece, Ireland, Italy and Spain would be the most dangerous since it would cause contagion to the French and Portuguese banking system in the first round and likely to German banks in the second round. At the same time, a simultaneous default of Greece, Ireland, Italy, Portugal and Greece, Ireland, Portugal, Spain would still be sustained by banking systems of the remaining countries.

Finally, Figure 6 shows how dangerous a hypothetical simultaneous default of all 
PIIGS would be for core countries' banking systems. It is seen that while in 2010 French and German banks are equally vulnerable to a default of all PIIGS, in 2011 the French banking system appears to be more fragile. Its ratio is above one and much higher than that of Germany. It could be explained by the fact that French banks have higher exposure to all PIIGS than German banks. As for the UK, its banking system is completely immune to cross-border contagion from PIIGS. It could be attributed to both the high capital of the UK banking system and its relatively lower exposure to PIIGS in comparison with French and German banks.

\section{Stress Testing Technique - Furfine Algorithm}

Researchers applied various methods to assess financial contagion. We use a stress testing technique that allows to track potential contagion paths and assess the associated capital losses of national banking systems. Drawing on the work of Degryse et al. (2010) and Chan-Lau (2010), we define contagion as a situation in which losses from claims to a defaulting country are able to lead to the failure of a banking system of another country. In practical terms, contagion occurs when the aggregate Tier 1 capital of at least one banking system in the network is insufficient to cover the losses resulting from its counterparty's failure to pay their foreign liabilities. Here, by losses we mean the product of a loss given default $\left(\mathrm{LGD}^{10}\right)$ and a banking system's exposure to a distressed foreign sovereign.

We exogenously trigger one sovereign at a time to find out how its failure affects banking systems of other countries via direct effects (outright failures) and knockon effects (failures from chain reaction). ${ }^{11}$ The contagion process may stop already after the first round if all banking systems have their aggregate Tier 1 capital higher than the incurred losses. However, contagion may spread further if one or more banking systems hold insufficient capital buffers to absorb the losses. In subsequent rounds, the algorithm considers combined losses from the failure of all sovereigns that occurred up to that point. The simulation is run round by round until the shock is completely absorbed or until the capital of all banking systems is depleted by losses. This contagion process is known as a Furfine algorithm (Furfine (1999)) and was initially applied to the US interbank market. The algorithm for the transmission of contagion across borders is presented in Figure 7.

\footnotetext{
${ }^{10}$ The term LGD is used to define the percentage of exposure that cannot be recovered as a result of bankruptcy. Thus, a 100\%-LGD would refer to the worst case scenario with zero recovery rates.

${ }^{11}$ In practice, however, several sovereigns can be hit by a shock simultaneously.
} 


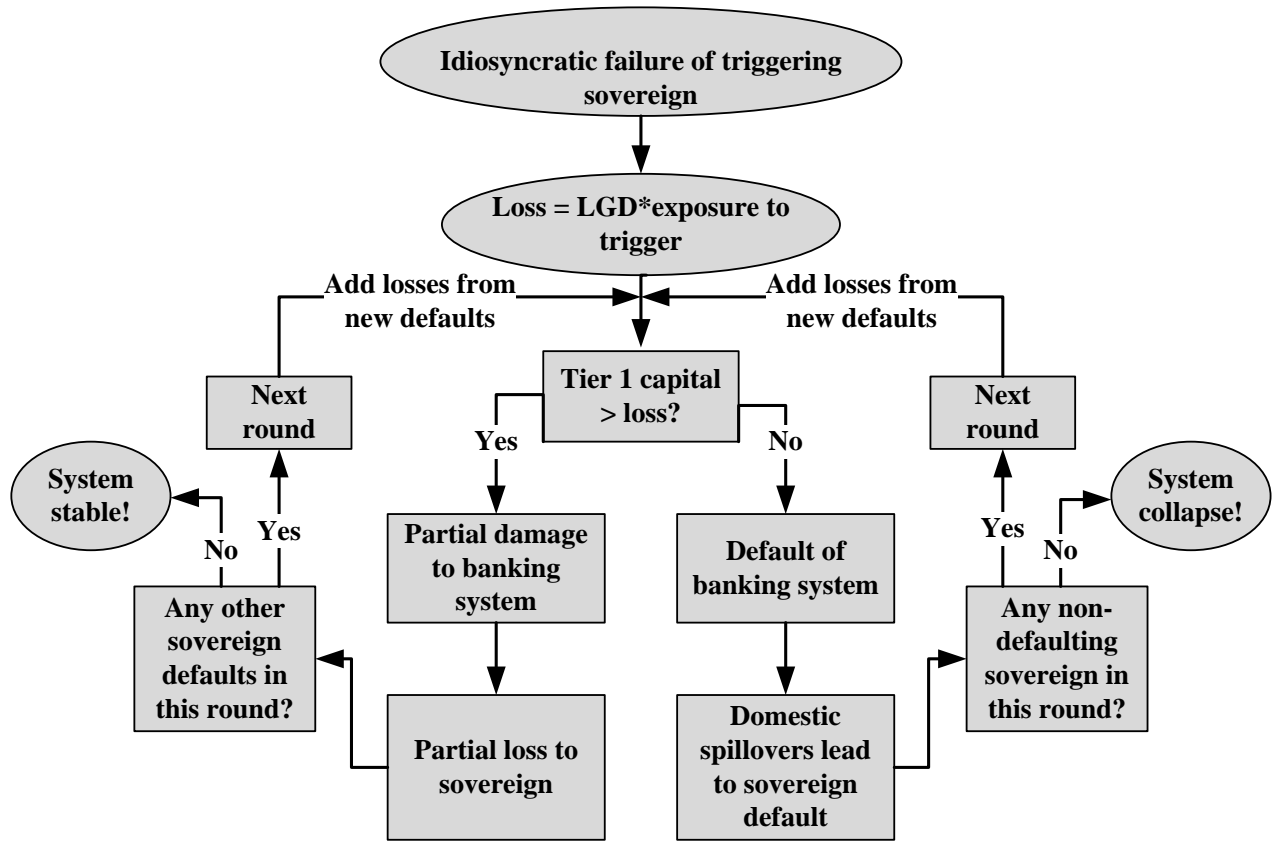

Figure 7: Propagation of financial contagion across borders Source: own elaboration based on Degryse et al. (2010).

An $N x N$ matrix of foreign exposures is obtained directly from the BIS consolidated banking statistics. In our analysis, we use gross exposures. Netting is not allowed since the data are reported at the aggregate level. ${ }^{12}$

$$
\begin{gathered}
X=\left[\begin{array}{ccccc}
x_{1,1} & \cdots & x_{1, j} & \cdots & x_{1, N} \\
\vdots & \ddots & \vdots & \cdot & \vdots \\
x_{i, 1} & \cdots & x_{i, j} & \cdots & x_{i, N} \\
\vdots & \ddots & \vdots & . & \vdots \\
x_{N, 1} & \cdots & x_{N, j} & \cdots & x_{N, N}
\end{array}\right] \\
a_{i}=\sum_{j=1}^{N} x_{i j} \text { and } l_{j}=\sum_{i=1}^{N} x_{i j},
\end{gathered}
$$

where $x_{i j}{ }^{13}$ is consolidated foreign claims of the banking system of country $i$ on all sectors (bank, non-bank and public sector) of country $j$ (alternatively, $x_{i j}$ shows

\footnotetext{
${ }^{12}$ Since 2010 the BIS started providing the data also at the sectoral level, i.e., banking systems' exposure to bank, non-bank and public sector, separately. Given the recent availability of these data, we use the aggregate data on banks' exposure, i.e., national banking system's exposure to all sectors (bank, non-bank and public sector) in another country.

${ }^{13}$ The diagonal elements of $x_{i j}$ are equal to zero since the BIS data do not show the exposure of
} 
liabilities of country $j$ to the banking system of country $i$ ); $N$ is the number of countries in the sample (20 countries in our case); $a_{i}$ is total foreign claims of the banking system of country $i$ on the rest of the countries; $l_{j}$ is total liabilities of country $j$ toward banking systems of the remaining countries.

Contagion occurs and the banking system of country $i$ fails if:

$$
C_{i}-\sum_{j=1}^{N} \lambda_{j} \theta x_{i j}<0
$$

where $C_{i}$ denotes the aggregate Tier 1 capital of the banking system $i ; \lambda_{j}$ is a dummy variable (has the value 1 if country $j$ defaults and is 0 otherwise); $\theta$ represents the level of LGD; $x_{i j}$ are the elements of matrix 1.

To conduct simulations round by round, we need to make some assumptions. First, since the data on the exposure of banking systems are available only at the aggregate level, we treat each banking system as a single institution. Second, our analysis takes the initial shocks to countries as given, i.e., the probability of the initial failure is the same for all the countries in the study. Third, losses from shocks directly affect the aggregate banking capital of a country, while in practice they can also be deducted from profit buffers. Fourth, to be able to run the Furfine algorithm for further rounds of contagion, as in Degryse et al. (2010) it is assumed that the failure of the banking system will eventually lead to the failure of the country through domestic spillovers. Fifth, as long as the aggregate capital of the banking system is positive after the shock, a country would remain solvent and thus would be able to fully meet its financial liabilities. In other words, it is assumed that when some banks fail as a result of the credit event, the surviving banks in the country take over their claims and liabilities. Sixth, given the difficulty in determining the appropriate level of LGD, we define it exogenously. We run simulations for four different values of the loss rate $(25 \%, 50 \%, 75 \%$ and $100 \%)$ and keep them constant over time, during all rounds of contagion and across all countries. ${ }^{14}$

a national banking system to the debt of its own country. However, in practice, banks tend to buy national sovereign debt. Thus, according to Blundell-Wignall and Slovik (2010), the exposure of Greek banks to the Greek sovereign debt constitutes $226 \%$ of their aggregate Tier 1 capital.

${ }^{14}$ However, Memmel et al. (2011) warn that assuming a constant loss rate tends to underestimate contagion risks and incurred losses for banking systems. The authors discuss other ways of determining LGD that may yield more precise results (stochastic and endogenous LGDs). In a similar vein, Takeyama et al. (2011) derive LGD estimates for the UK banks on the basis of the data on 


\section{Simulation Results}

As we mentioned earlier, our primary interest lies in the study of contagion in Europe. However, in order to account for all potential contagion paths, it is important to have a full picture of the linkages that form a network. Therefore, following our preliminary data analysis for eight countries (Portugal, Ireland, Italy, Greece, Spain (PIIGS), France, Germany and the UK (core countries)), we run the algorithm for an extended sample of 20 countries that report their data on banking systems' exposure on the ultimate risk basis. These reporting countries are Australia, Austria, Belgium, Canada, Finland, France, Germany, Greece, India, Ireland, Italy, Japan, the Netherlands, Portugal, Spain, Sweden, Switzerland, Turkey, the UK and the US. ${ }^{15}$ Chile was excluded from the analysis since the exposure of its banks to most of the countries is unknown. Besides, the data on the exposure of the Finnish banking system are not available for 2006-2009. Thus, for this period Finland was considered only as a potential triggering country, however, we cannot draw any conclusions on how vulnerable Finnish banks were during 2006-2009. In a similar vein, Canadian banks' vulnerability to contagion is unknown for 2006-2009 since we were unable to collect the appropriate data on Tier 1 capital for this period.

In our simulations we consider two cases: 1 . when a shock is absorbed by the capital of all banks in the country and 2. when only large banks in the country are considered as a cushion. Similar to Mistrulli (2011), we define a large bank as a bank with at least $\$ 20$ billion of total assets.

\subsection{Stress Testing with all Banks as a Cushion}

\subsubsection{Extent of Contagion Effects}

The first set of our analysis identifies the extent of contagion effects reflected in the number of potential defaults, the main shock transmitters and the most vulnerable to contagion banking systems. Results of the simulations for different levels of LGD are presented in Table 7 in the Appendix. The table enlists only those countries that

CDS spreads and probabilities of default calculated from stock option prices. The authors show that LGD plays an important role in CDS pricing. Furthermore, they argue that LGD does not remain constant in time and varies for different entities. Thus, the variability of LGD should be considered in order to correctly determine credit risk from the CDS market.

${ }^{15}$ It is possible to study contagion also from non-reporting countries in the BIS statistics. However, only the exposure of reporting countries' banking systems to non-reporting countries is available; while the data on the exposure of non-reporting countries' banks are unknown. For this reason, we do not include non-reporting countries in our analysis. 
would trigger contagion at least once during the studied period. Two figures were extracted from this table.

Figure 8 shows changes in the number of outright (first-round) and total (all-round) defaults as a result of contagion during 2006-2011. Interestingly, the contagious potential of the network has been decreasing between 2006 and 2009. It could possibly be explained by the retrenchment of capital flows around the world and by the recapitalization of national banking systems in the aftermath of the global financial crisis. However, at the end of 2009, with the escalation of the European sovereign debt crisis, the number of potential defaults started growing again. Besides, the frequency of failures increases with higher LGDs.
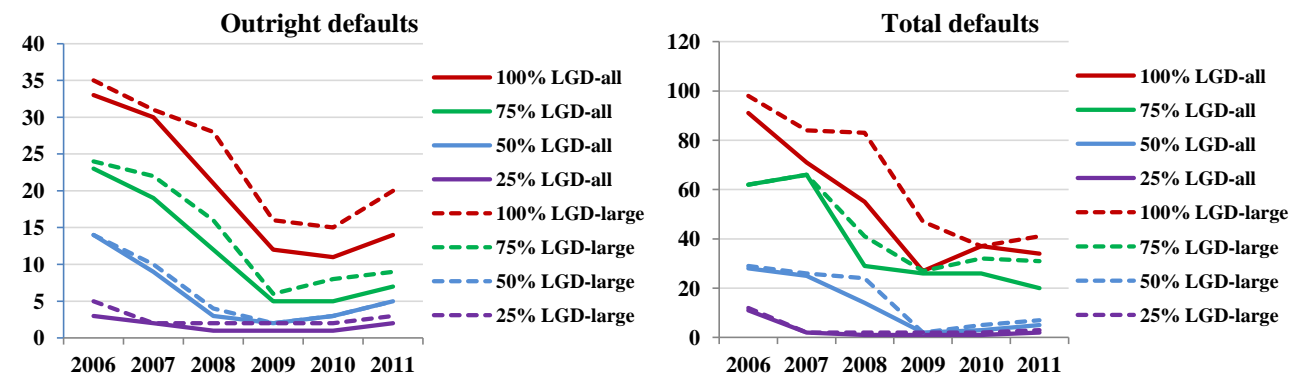

Figure 8: Number of outright failures (left) and total defaults (right) Note: The results are displayed with straight lines (dashed lines) for the case when all banks are exposed to shocks (only large banks are exposed to shocks).

Source: own elaboration based on Tables 6 and 7 in the Appendix.

Figure 9 illustrates the main contagion propagators and the number of defaults caused by them for each year and various levels of LGD. Thus, contagion could be triggered at least once during the studied period by 12 out of 20 countries in the examined network: Ireland, Italy, Spain, France, Germany, the UK, the US, Belgium, Finland, the Netherlands, Japan and Turkey. However, there are noticeable differences across triggering countries in the number of spillovers and the frequency of their potential occurrence.

As can be seen from the figure, the number of triggering countries varies across the years. For instance, with 100\% LGD in 2006 and 2007 contagion could be triggered by eleven and ten countries, respectively; whereas in 2010 only four and in 2011 only five countries would be contagious. The main propagators of spillovers are the US and the UK. Thus, in 2011 with $100 \%$ of LGD a shock to the US is capable of triggering contagion to up to 16 banking systems (with seven banking systems defaulting already in the first round). The US appears to be contagious through the 

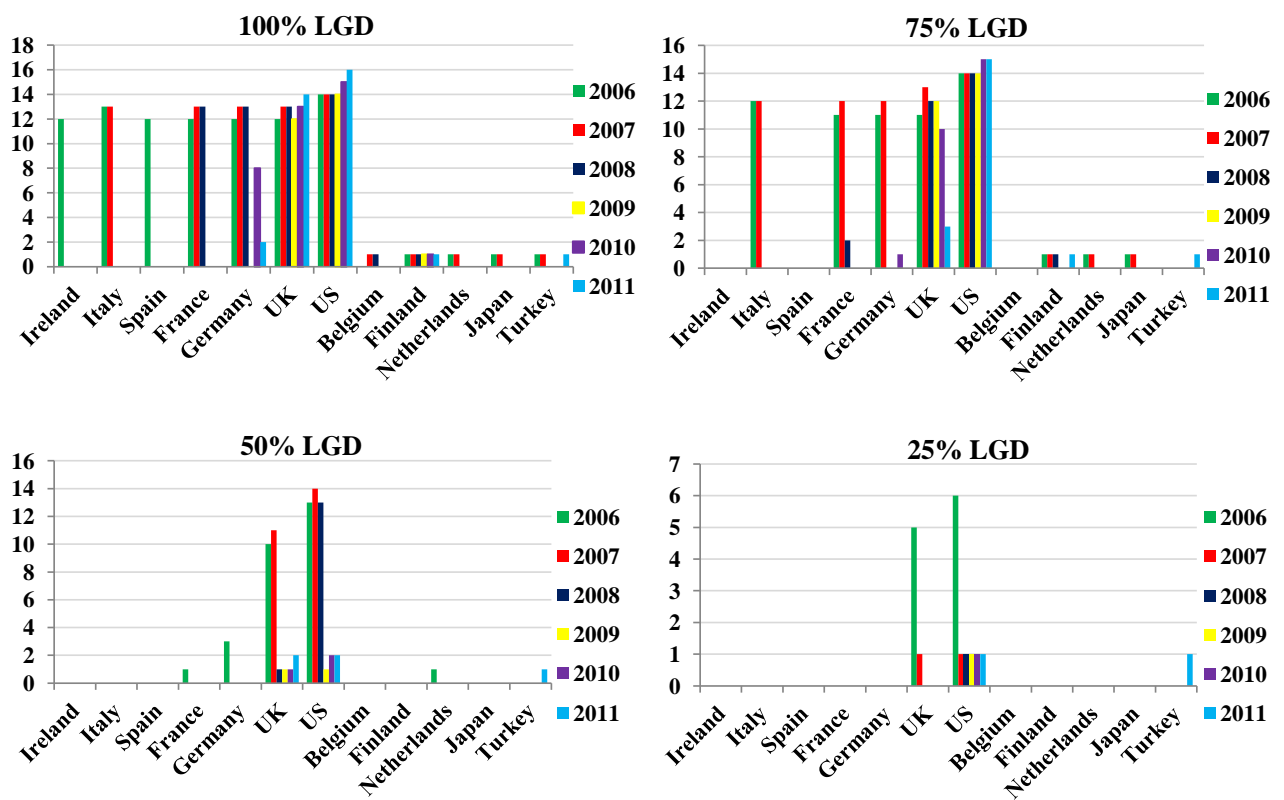

Figure 9: Number of induced failures by triggering countries (all banks exposed) Source: own elaboration based on Table 6 in the Appendix.

whole period of time contemplated in this study and even with $25 \%$ of LGD. The UK's potential for contagion is also substantial, however, with $25 \%$ of a loss rate it is capable of transmitting shocks only in 2006 and 2007. These findings on the systemic importance of the UK and the US are consistent with the results of Chan-Lau (2010) and Degryse et al. (2010).

Regarding core Eurozone countries, Germany and France seem to pose the highest threat to the stability of the system. However, on average, a shock to them would translate into a less frequent and lower number of failures than a shock to the US and the UK. Interestingly, Germany is capable of triggering contagion more often than France. Thus, with 100\% LGD Germany appears to be contagious every year except 2009, whereas France is dangerous only in 2006-2008. Belgium, Finland and the Netherlands could trigger contagion to one banking system, but with no secondround effects.

As to PIIGS, only Ireland, Italy and Spain are able to cause occasional contagion effects. Ireland and Spain could transmit a shock up to 12 banking systems in 2006 but only with 100\% LGD. Italy appears to be contagious both in 2006 and in 2007 leading to up to 13 defaults with $100 \%$ and 12 defaults with $75 \%$ of LGD. At the same time, a shock to Portugal and Greece does not result in additional failures. Among other triggers, Japan and Turkey could lead to a failure of one banking system. 
Figure 10 depicts each country's vulnerability level characterized by a number of simulations, in which its banking system defaults. It is rather difficult to distinguish the most vulnerable banking systems with $100 \%$ of LGD. However, by looking at the results with lower levels of a loss rate, it is clear that there exist considerable risks for Switzerland and Ireland. The Swiss banking system defaults through the whole period even with $25 \%$ of LGD. Irish banks are also quite vulnerable as they are affected at least twice with $25 \%$ of LGD. At the same time, banking systems of the US, Turkey and Finland ${ }^{16}$ are completely immune to contagion effects occurring in the studied network. We can also observe a rather low degree of contagion to Indian and Greek banks, even though they are not completely resilient to shocks. ${ }^{17}$

Potential first-round and all-round contagion paths for the worst case scenario are displayed in Figures 11 - 16. For each year grey boxes ${ }^{18}$ of the figures show triggering countries and corresponding banking systems vulnerable to contagion from them. The left panel features first-round effects, whereas the right panel shows the accumulated effects after all rounds of contagion.

The right panel of the figures clearly demonstrates that there can be distinguished two groups of triggers in terms of their tendency to spread contagion after all rounds have been accounted for. The first group is capable of spreading contagion to banking systems of most of the countries in the studied network and is represented by Ireland, Italy, Spain, France, Germany, ${ }^{19}$ the UK and the US. Even though the frequency of contagion from these countries differs substantially, in most of the cases when contagion does occur, very few banking systems remain resilient after all rounds (e.g., the US, Turkish, Indian (apart from 2006) and Finnish banks). An interesting finding is that a shock to the US is capable of depleting the capital of the UK banking system already in the first round, whereas the UK would not lead to the failure of the US banking system even after all rounds of contagion.

The second group of triggers is capable of spreading contagion effects only to one particular banking system and is represented by Finland, the Netherlands, Belgium, Turkey and Japan. Thus, a shock to Finland would put a burden on the Swedish

\footnotetext{
${ }^{16}$ The vulnerability of the Finnish and Canadian banking system is known only for 2010 and 2011.

${ }^{17}$ For example, in 2011 the Greek banking system is the most vulnerable in the network as its aggregate Tier 1 capital is extremely low for that period.

${ }^{18}$ Black boxes show additional contagion effects for the case when only large banks of a country serve as a cushion.

${ }^{19}$ However, in 2011 the potential of Germany to trigger contagion is limited to banking systems of only two countries - the Netherlands in the first round and Greece in the second round.
} 

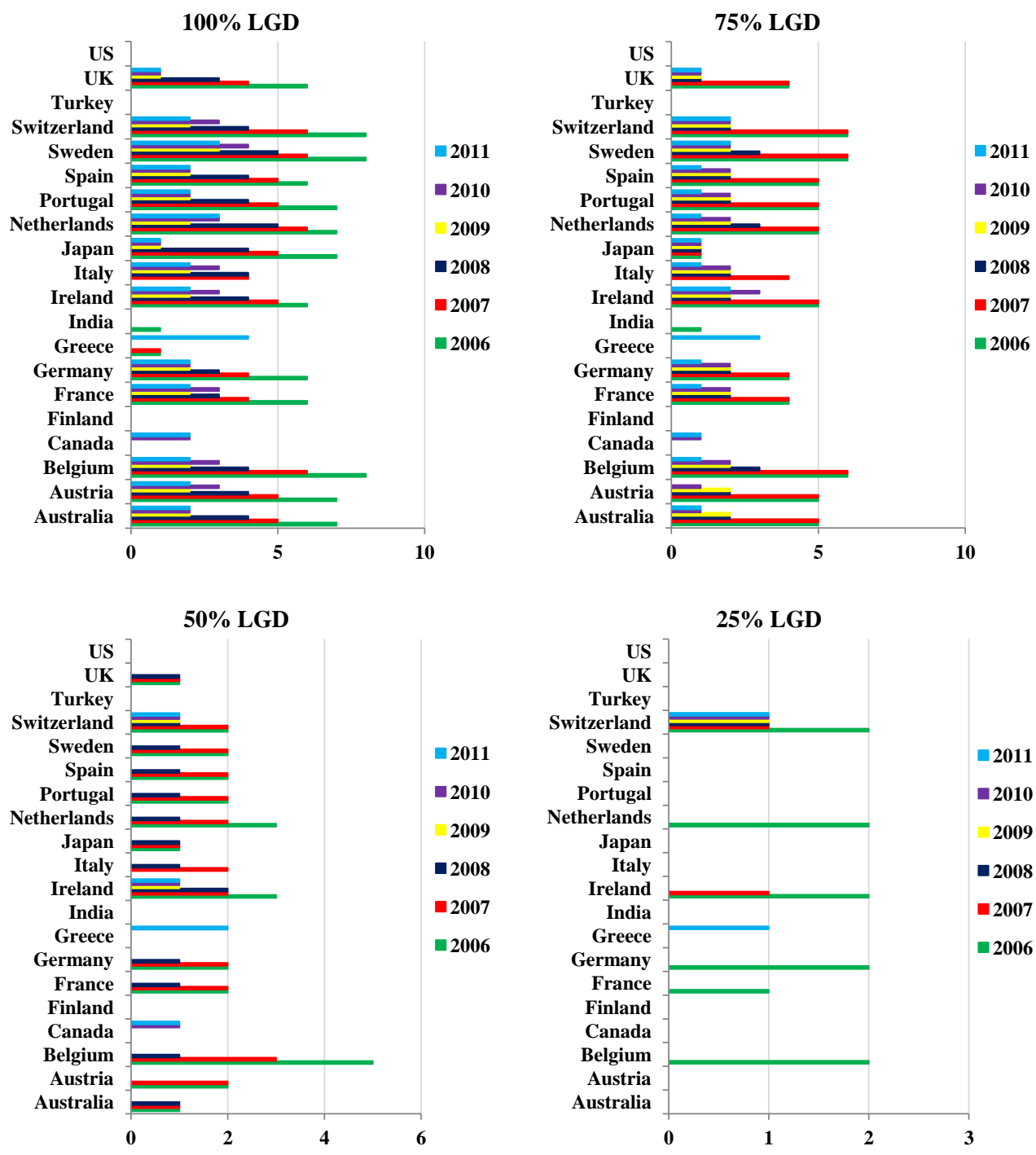

Figure 10: Vulnerability of countries (all banks exposed) Source: own calculations based on the BIS and Bankscope data.

banking system through the whole period, however, there is no contagion in the opposite direction - from Sweden to Finnish banks. Turkey would destroy the Greek banking system in 2006, 2007 and 2011. The Netherlands is capable of spreading contagion to Belgium banks in 2006 and 2007, and Belgium is contagious for the Dutch banking system in 2007 and 2008. While the above contagion effects could be explained in terms of the regional proximity of the countries, it is somewhat surprising that a shock to Japan would put on edge the Swiss banking system in 2006 and 2007. 

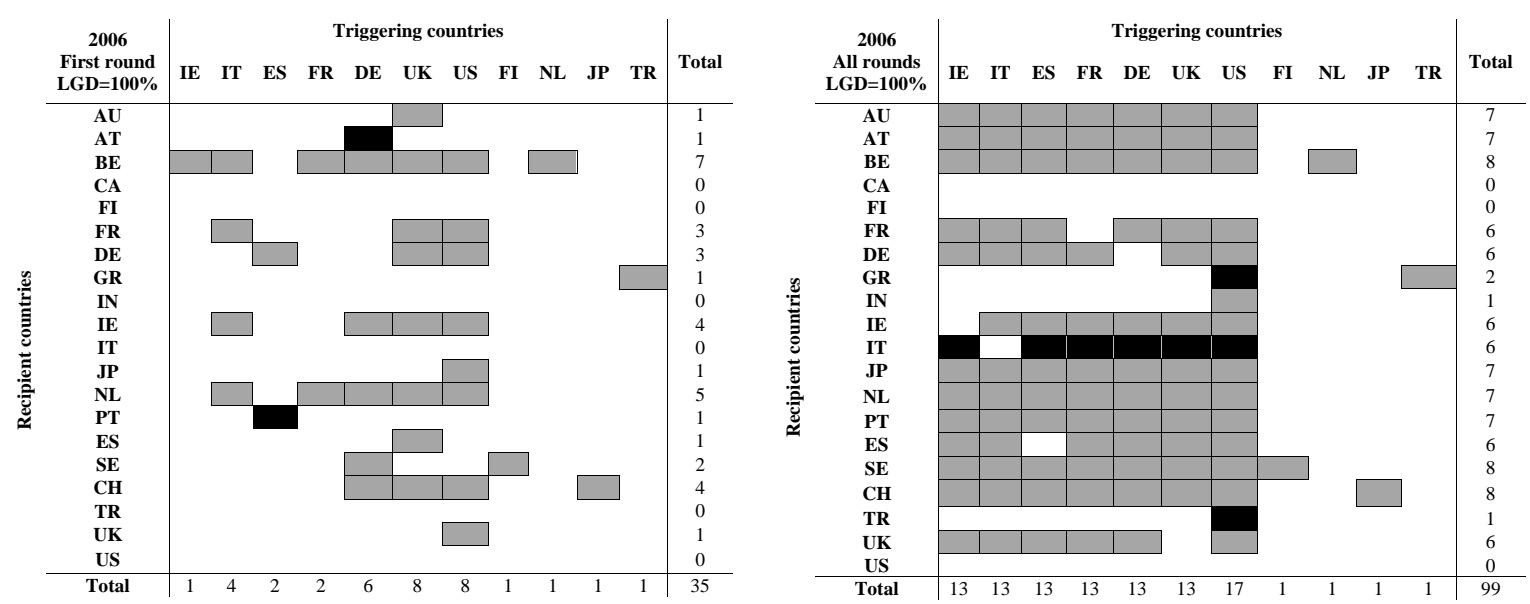

Figure 11: First-round defaults (left) and all-round defaults (right) in 2006 Note: black boxes show additional contagion effects for the case when only large banks serve as a cushion.

Country abbreviations: $\mathrm{AU}=$ Australia, $\mathrm{AT}=$ Austria, $\mathrm{BE}=$ Belgium, $\mathrm{CA}=$ Canada, $\mathrm{FI}=$ Finland, $\mathrm{FR}=$ France, $\mathrm{DE}=$ Germany,$\quad \mathrm{GR}=$ Greece,$\quad \mathrm{IN}=$ India,$\quad \mathrm{IE}=$ Ireland, $\mathrm{IT}=\mathrm{Italy}, \quad \mathrm{JP}=$ Japan, $\mathrm{NL}=$ Netherlands, $\mathrm{PT}=$ Portugal, $\mathrm{ES}=$ Spain, $\mathrm{SE}=$ Sweden, $\mathrm{CH}=$ Switzerland, $\mathrm{TR}=$ Turkey, UK=United Kingdom, US=United States.

Source: own calculations based on the BIS and Bankscope data.
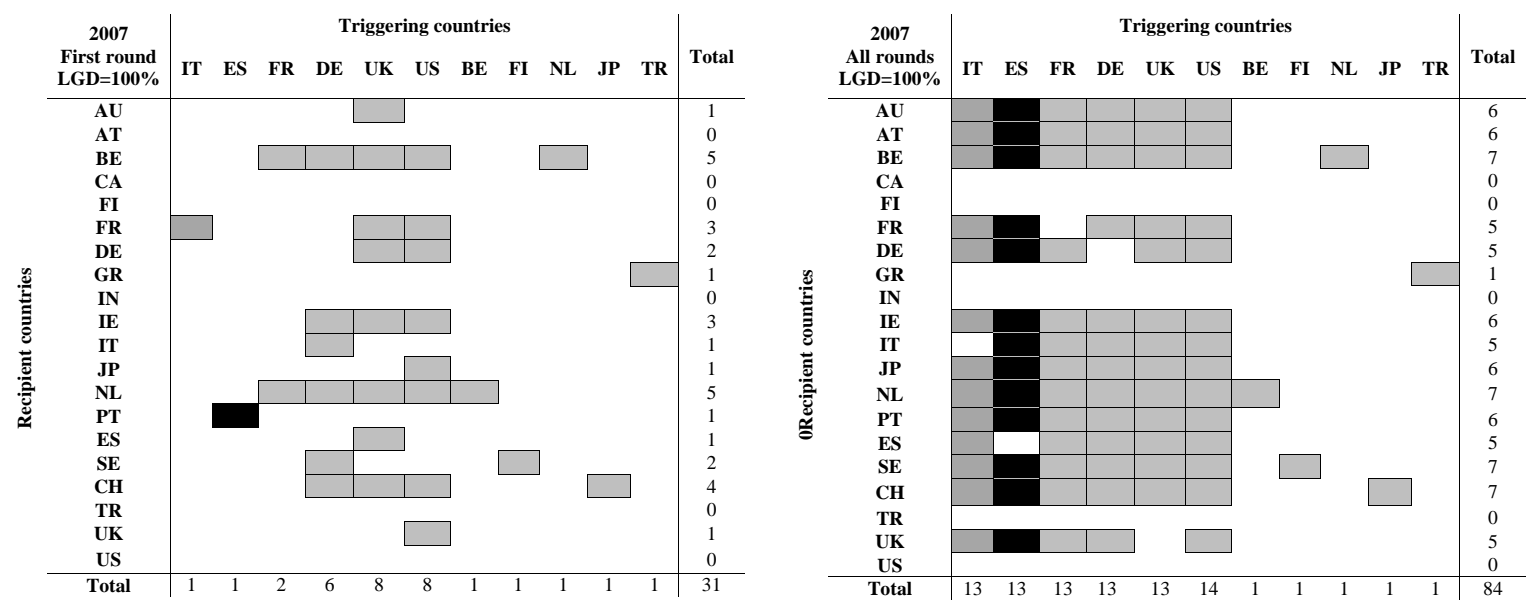

Figure 12: First-round defaults (left) and all-round defaults (right) in 2007 Note: black boxes show additional contagion effects for the case when only large banks serve as a cushion.

Country abbreviations: $\mathrm{AU}=$ Australia, $\mathrm{AT}=$ Austria, $\mathrm{BE}=$ Belgium, $\mathrm{CA}=$ Canada, $\mathrm{FI}=$ Finland, $\mathrm{FR}=$ France, $\mathrm{DE}=$ Germany,$\quad \mathrm{GR}=$ Greece, $\mathrm{IN}=$ India,$\quad \mathrm{IE}=$ Ireland, $\mathrm{IT}=$ Italy, $\mathrm{JP}=\mathrm{Japan}, \quad \mathrm{NL}=$ Netherlands, $\mathrm{PT}=$ Portugal, $\mathrm{ES}=$ Spain, $\mathrm{SE}=$ Sweden, $\mathrm{CH}=$ Switzerland, $\mathrm{TR}=$ Turkey, $\mathrm{UK}=$ United Kingdom, US=United States .

Source: own calculations based on the BIS and Bankscope data. 

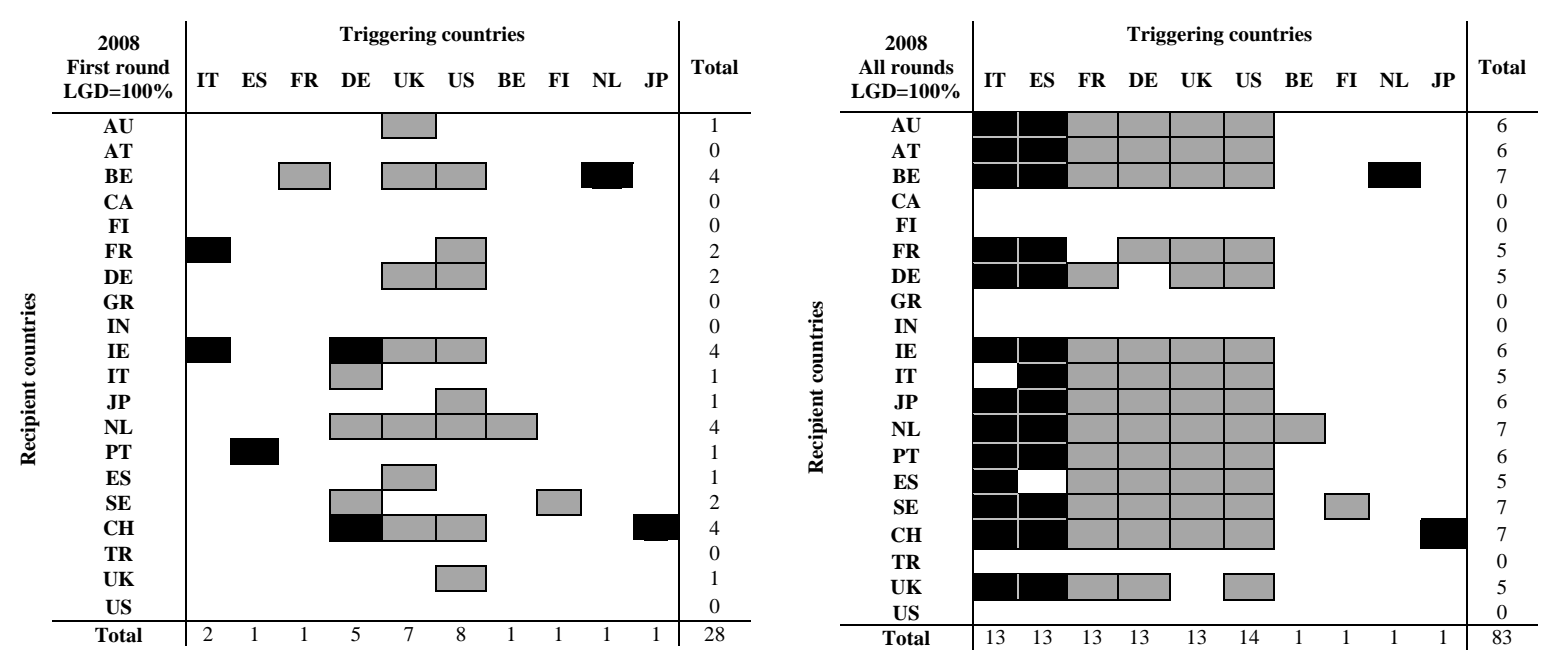

Figure 13: First-round defaults (left) and all-round defaults (right) in 2008 Note: black boxes show additional contagion effects for the case when only large banks serve as a cushion.

Country abbreviations: $\mathrm{AU}=$ Australia, $\mathrm{AT}=$ Austria, $\mathrm{BE}=$ Belgium, $\mathrm{CA}=\mathrm{Canada}, \quad \mathrm{FI}=\mathrm{Finland}, \quad \mathrm{FR}=\mathrm{France}$, $\mathrm{DE}=$ Germany,$\quad \mathrm{GR}=$ Greece,$\quad \mathrm{IN}=$ India,$\quad \mathrm{IE}=$ Ireland, $\mathrm{IT}=\mathrm{Italy}, \quad \mathrm{JP}=\mathrm{Japan}, \quad \mathrm{NL}=\mathrm{Netherlands}, \quad \mathrm{PT}=\mathrm{Portugal}$, $\mathrm{ES}=$ Spain, $\mathrm{SE}=$ Sweden, $\mathrm{CH}=$ Switzerland, $\mathrm{TR}=$ Turkey, UK=United Kingdom, US=United States.

Source: own calculations based on the BIS and Bankscope data.
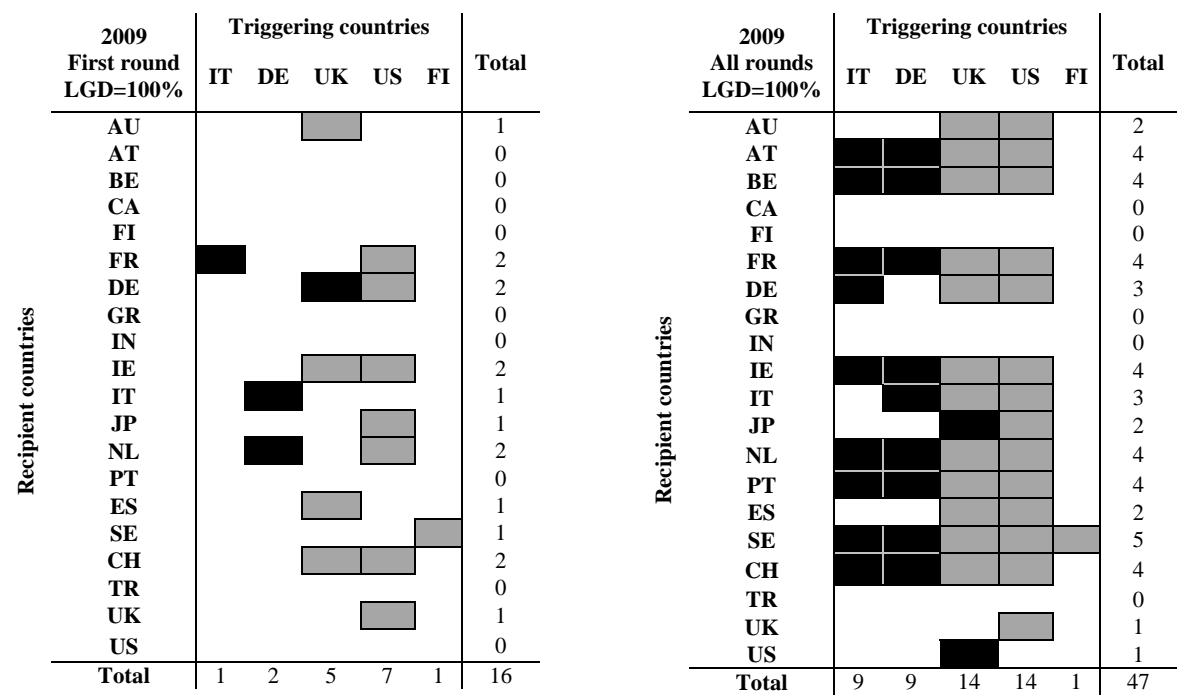

Figure 14: First-round defaults (left) and all-round defaults (right) in 2009

Note: black boxes show additional contagion effects for the case when only large banks serve as a cushion.

Country abbreviations: $\mathrm{AU}=$ Australia, $\mathrm{AT}=$ Austria, $\mathrm{BE}=$ Belgium, $\mathrm{CA}=\mathrm{Canada}, \quad \mathrm{FI}=\mathrm{Finland}, \quad \mathrm{FR}=\mathrm{France}$, $\mathrm{DE}=$ Germany,$\quad \mathrm{GR}=$ Greece,$\quad \mathrm{IN}=$ India,$\quad \mathrm{IE}=$ Ireland $, \quad \mathrm{IT}=\mathrm{Italy}, \quad \mathrm{JP}=\mathrm{Japan}, \quad \mathrm{NL}=$ Netherlands,$\quad \mathrm{PT}=\mathrm{Portugal}$, $\mathrm{ES}=$ Spain, $\mathrm{SE}=$ Sweden, $\mathrm{CH}=$ Switzerland, $\mathrm{TR}=$ Turkey, UK=United Kingdom, US=United States.

Source: own calculations based on the BIS and Bankscope data. 

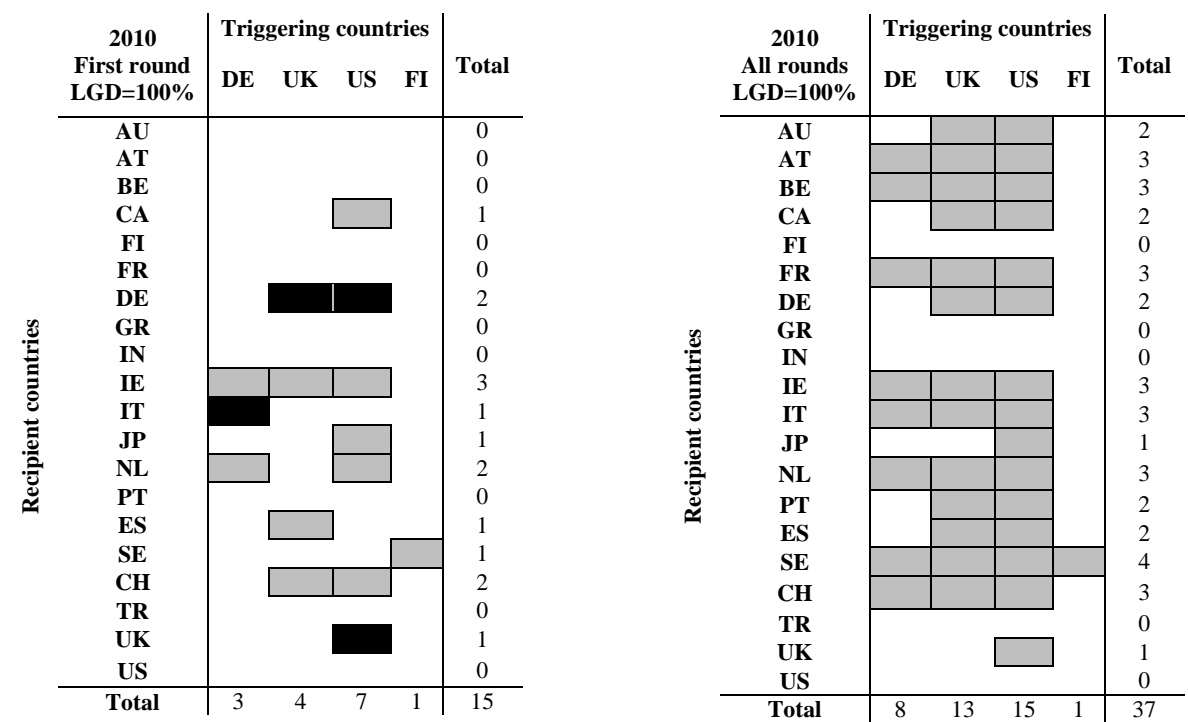

Figure 15: First-round defaults (left) and all-round defaults (right) in 2010

Note: black boxes show additional contagion effects for the case when only large banks serve as a cushion.

Country abbreviations: $\mathrm{AU}=$ Australia, $\mathrm{AT}=$ Austria, $\mathrm{BE}=$ Belgium, $\mathrm{CA}=\mathrm{Canada}, \quad \mathrm{FI}=\mathrm{Finland}, \quad \mathrm{FR}=\mathrm{France}$, $\mathrm{DE}=$ Germany,$\quad \mathrm{GR}=$ Greece,$\quad \mathrm{IN}=$ India,$\quad \mathrm{IE}=$ Ireland, $\mathrm{IT}=\mathrm{Italy}, \quad \mathrm{JP}=\mathrm{Japan}, \quad \mathrm{NL}=$ Netherlands,$\quad \mathrm{PT}=\mathrm{Portugal}$, $\mathrm{ES}=$ Spain, $\mathrm{SE}=$ Sweden, $\mathrm{CH}=$ Switzerland, $\mathrm{TR}=$ Turkey, UK=United Kingdom, US=United States.

Source: own calculations based on the BIS and Bankscope data.
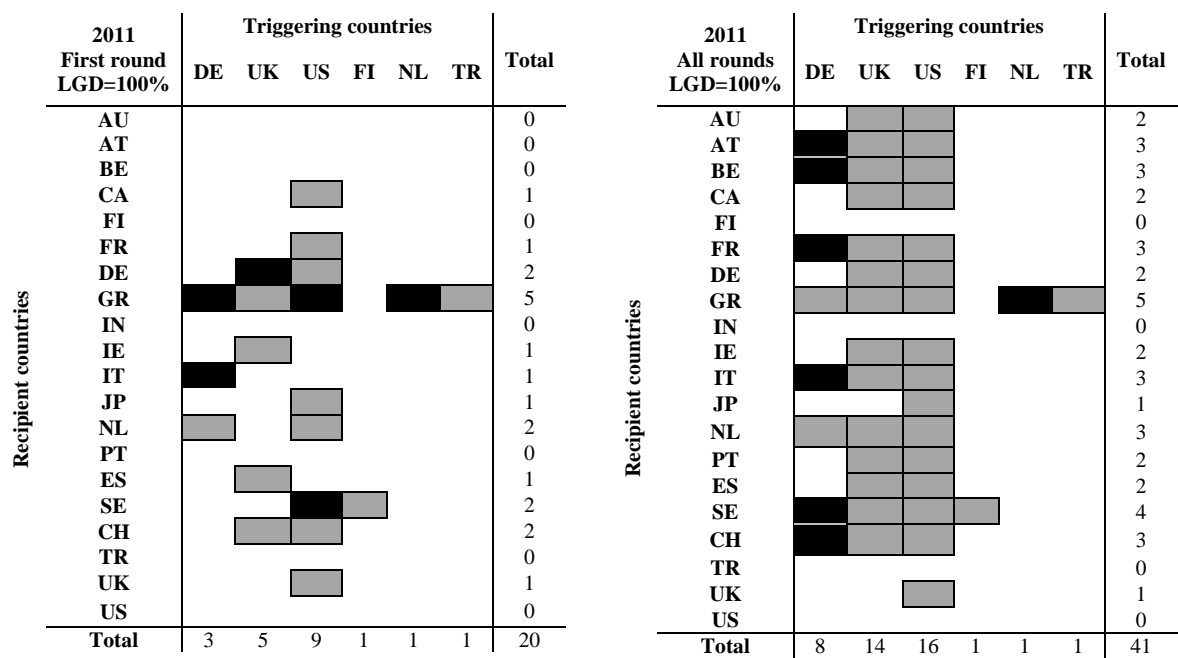

Figure 16: First-round defaults (left) and all-round defaults (right) in 2011

Note: black boxes show additional contagion effects for the case when only large banks serve as a cushion.

Country abbreviations: $\mathrm{AU}=$ Australia, $\mathrm{AT}=$ Austria, $\mathrm{BE}=$ Belgium, $\mathrm{CA}=$ Canada, $\mathrm{FI}=$ Finland, $\mathrm{FR}=$ France,$\quad \mathrm{DE}=$ Germany,$\quad \mathrm{GR}=$ Greece,$\quad \mathrm{IN}=$ India,$\quad \mathrm{IE}=$ Ireland, $\quad \mathrm{IT}=\mathrm{Italy}, \quad \mathrm{JP}=\mathrm{Japan}$, $\mathrm{NL}=$ Netherlands,$\quad \mathrm{PT}=$ Portugal, $\mathrm{ES}=$ Spain, $\mathrm{SE}=$ Sweden,$\quad \mathrm{CH}=$ Switzerland, $\quad \mathrm{TR}=$ Turkey, UK=United Kingdom, US=United States.

Source: own calculations based on the BIS and Bankscope data. 
The left panel of the figures shows that banking systems of Belgium, the Netherlands, Switzerland and Ireland are the most directly exposed to contagion during various years. For instance, in 2006 Belgium banks default seven times in the first round, the Dutch banking system is triggered five times and the Swiss and Irish banks experience contagion four times in the first round. Interestingly, in 2011 along with the Dutch and Swiss banking systems Greek banks also appear to be vulnerable to first-round effects. Besides, in 2011 the Greek banking system seems to be the most fragile after all rounds of contagion as four countries would be able to lead to its default - Turkey, Germany, the UK and the US.

\subsubsection{Losses of Capital}

Following the identification of potential contagion paths, we devote the second set of our analysis to the calculation of capital losses as a result of contagion. The capital of a banking system may not be fully depleted as a result of a shock to another country and, according to our definition, contagion would not occur. However, a large share of the capital loss could substantially undermine the function of national banks due to indirect effects (e.g., bank runs from depositors, downgrades of credit ratings). Network analysis allows to measure to which extent shocks would damage the system. Here we illustrate the highest possible impact of a shock with a maximum loss rate of $100 \%$.

Table 1 presents banking systems' capital losses after all rounds of contagion for 2011. As expected, the US and the UK pose the highest threat to banking systems of other countries. A shock to Germany would be highly dangerous for Italian banks since it would destroy up to $92 \%$ of their capital. Besides, Germany could fail $75.4 \%$ of the capital of French banks, while capital losses to German banks from a shock to France would not exceed $36.4 \%$. Another interesting finding is that a shock to Italy would be suffered the most by the French banking system (67.7\% of its Tier 1 capital would be depleted).

At the same time, a shock to Greece, Portugal, Sweden and India would cause minor losses to banks of other countries. For instance, the highest loss that a shock to Greece would cause is to Portuguese banks (22.4\% of Tier 1 capital) and French banks (9\%). A shock to Portugal would mostly affect Spanish banks and deplete $24.3 \%$ of their capital, whereas a shock to Spain would destroy $63.8 \%$ of the capital of Portuguese banks. 


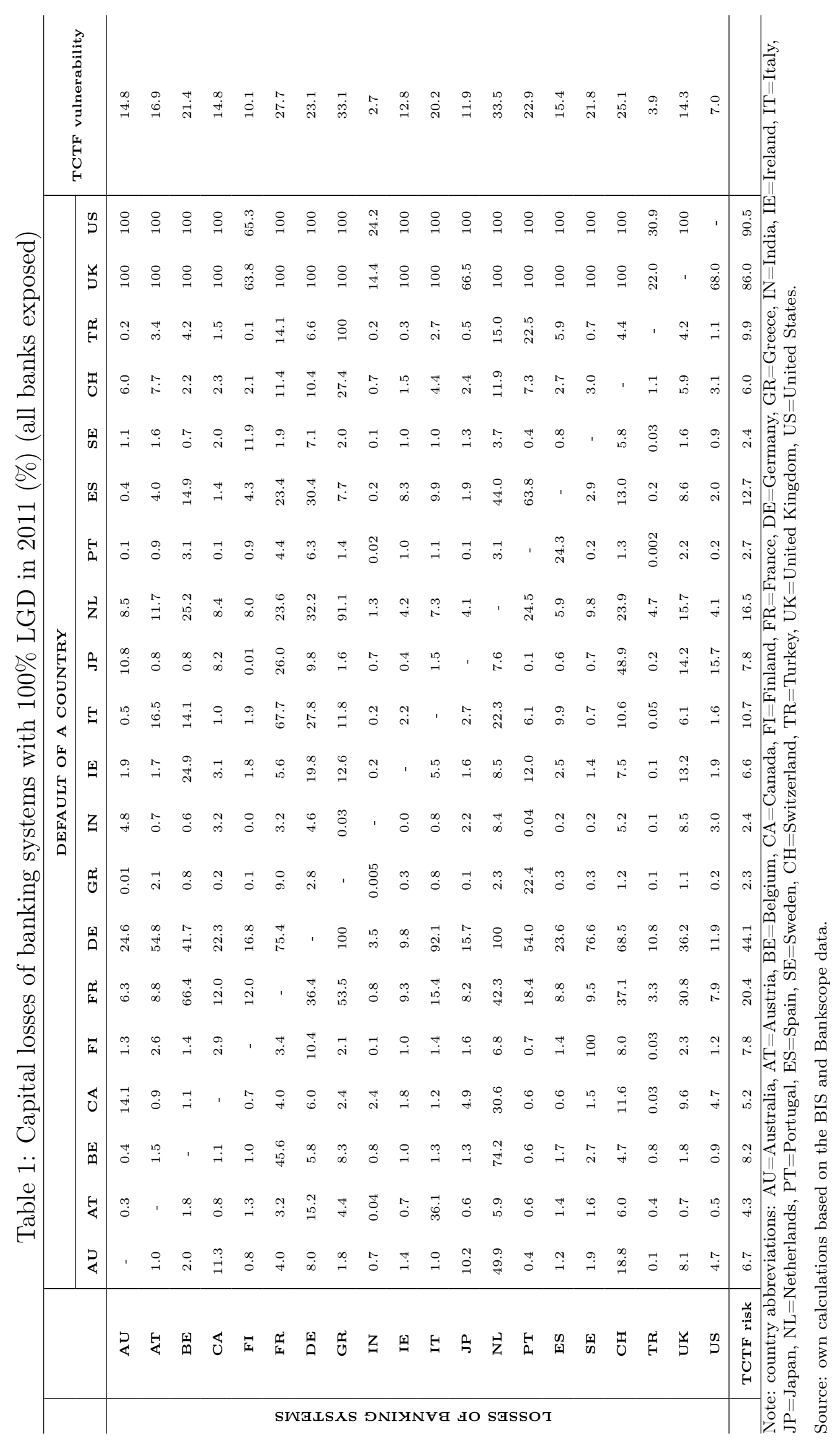


On the basis of Table 1 and similar tables for other years that are not presented here we also estimate too-connected-to- fail (TCTF) risk and TCTF vulnerability defined by Chan-Lau (2010). TCTF risk refers to the average capital loss induced by the failure of a given country on banking systems of other countries, whereas TCTF vulnerability measures the average capital loss suffered by the banking system due to shocks in other countries.

Table 2 allows to compare TCTF risk of the countries against TCTF vulnerability of their banking systems. Thus, it can be seen that for most of the countries the risk they pose is lower than the vulnerability of their banks to shocks (e.g., Australia, Austria, Belgium, Canada, Finland, Greece, India, Japan, the Netherlands, Portugal, Sweden and Switzerland). However, it is not surprising that for the UK, the US and Germany the opposite is true, i.e., TCTF risk exceeds TCTF vulnerability. For countries like France, Ireland, Italy, Spain and Turkey in some years the risk is higher, while in other times vulnerability exceeds the risk.

The table also shows that the highest TCTF risk is posed by the UK, the US, Germany and France, while the lowest risk is triggered by Sweden and India. As for TCTF vulnerability, it is the lowest for the the US, Turkish and Indian banks. It is also quite low for the UK and Greek banking systems, however, for Greek banks it increased considerably in 2011. Among the most TCTF-vulnerable banking systems are those of Switzerland, the Netherlands, Belgium, Sweden as well as France and Germany.

Following the calculation of capital losses caused by countries to banking systems on a bilateral basis, in Table 3 we feature the share of total Tier 1 capital of the system that could be failed by each potential trigger as a result of all contagion rounds. ${ }^{20}$ Figure 17 emerges from this table and presents the most characteristic results. It is not surprising that a shock to the US, the UK, Germany and France would incur the highest systemic losses. The US is capable of destroying up to $97 \%$ of total Tier 1 capital. The potential of the UK is also high but slightly lower than that of the US (on average, the UK is able to destroy $78 \%$ of the systemic capital). Interestingly, in 2009 France experienced a large drop in its potential to fail capital (from $78.9 \%$ in 2008 to $19.1 \%$ in 2009), whereas Germany first showed a downward trend between 2007 and 2009 and then experienced an unexpected jump in its systemic importance in 2010 (from $28.2 \%$ in 2009 to $57.2 \%$ in 2010 ).

\footnotetext{
${ }^{20}$ Calculations are done for total Tier 1 capital of banking systems of all the countries in the network excluding the triggering sovereign.
} 


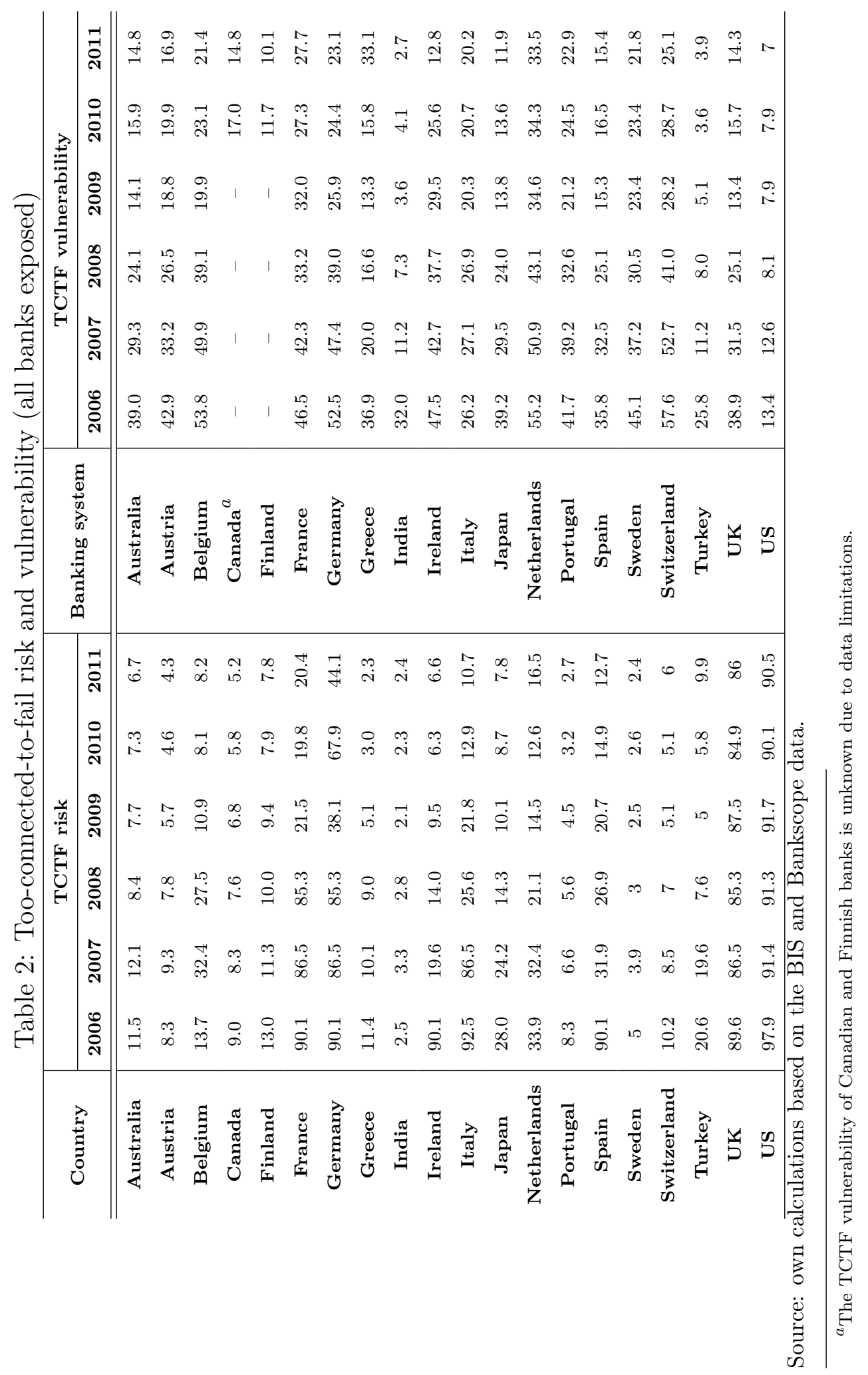


Table 3: Share of failed total capital excluding the trigger (100\% LGD, all banks exposed)

\begin{tabular}{|c|c|c|c|c|c|c|}
\hline Country & 2006 & 2007 & 2008 & 2009 & 2010 & 2011 \\
\hline Australia & 9.2 & 10.6 & 7.5 & 7.5 & 7.2 & 7.1 \\
\hline Austria & 4.3 & 6.8 & 6.1 & 4.7 & 3.6 & 3.4 \\
\hline Belgium & 9.1 & 24.9 & 20.8 & 9.6 & 6.5 & 6.3 \\
\hline Canada & 6.9 & 7.4 & 6.4 & 6.4 & 5.8 & 5.8 \\
\hline Finland & 6.0 & 5.5 & 4.5 & 4.5 & 4.0 & 3.9 \\
\hline France & 70.6 & 79.9 & 78.9 & 19.1 & 17.0 & 16.0 \\
\hline Germany & 71.1 & 80.1 & 76.1 & 28.2 & 57.2 & 30.7 \\
\hline Greece & 5.0 & 5.0 & 4.8 & 3.2 & 1.9 & 1.3 \\
\hline India & 2.5 & 3.6 & 3.1 & 2.9 & 3.4 & 3.6 \\
\hline Ireland & 72.2 & 15.2 & 12.2 & 9.3 & 6.2 & 5.6 \\
\hline Italy & 73.2 & 80.2 & 20.6 & 18.1 & 12.3 & 10.3 \\
\hline Japan & 21.5 & 22.3 & 14.4 & 13.0 & 13.5 & 13.2 \\
\hline Netherlands & 22.3 & 23.6 & 14.1 & 11.1 & 10.2 & 10.4 \\
\hline Portugal & 4.6 & 4.5 & 4.1 & 3.8 & 2.8 & 2.4 \\
\hline Spain & 71.2 & 20.1 & 17.2 & 14.6 & 10.0 & 8.4 \\
\hline Sweden & 3.2 & 3.0 & 2.3 & 2.2 & 2.0 & 1.8 \\
\hline Switzerland & 6.9 & 6.6 & 5.4 & 5.0 & 4.4 & 4.7 \\
\hline Turkey & 7.7 & 7.7 & 2.3 & 1.9 & 2.1 & 3.5 \\
\hline UK & 68.1 & 78.4 & 74.6 & 87.8 & 80.4 & 79.7 \\
\hline US & 97.8 & 97.6 & 97.5 & 97.4 & 97.6 & 97.3 \\
\hline
\end{tabular}

Source: own calculations based on the BIS and Bankscope data.

Regarding PIIGS, both Ireland and Spain in 2006 and Italy in 2006 and 2007 have a very high potential to destroy capital (more than 70\%). However, later they followed a downward trend and became less important systemic players. The potential of Greece, Portugal, Sweden and India remains among the lowest through the whole period.

Following Wells (2004), we finish our analysis by distinguishing five groups of affected banking systems according to the percent of their capital losses: banking systems losing $5-10 \%, 10-20 \%, 20-50 \%, 50-100 \%$ and $100 \%$ of their Tier 1 capital (i.e., defaulting). Figure 18 presents the dynamics of each group over time with 100\% LGD. Thus, the number of banking systems losing their entire Tier 1 capital has dropped considerably from 2006 to 2009 and then slightly increased again. The number of banks losing 50-100\% has been also decreasing between 2006 and 2011. On the other hand, the number of banking systems losing only $5-10 \%$ of their capital follows an upward trend (with a slight decrease in 2010). Thus, between 2006 and 2008 there were more banking systems whose capital was depleted by 100\%, whereas in 2008-2011 the 

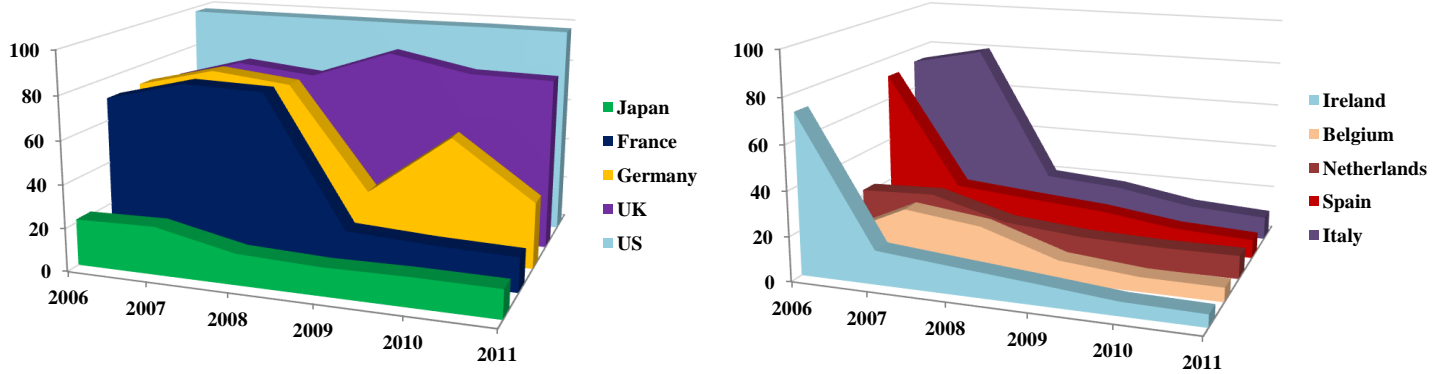

Figure 17: Share of failed total capital with 100\% LGD (all banks exposed) Source: own elaboration based on Table 3.

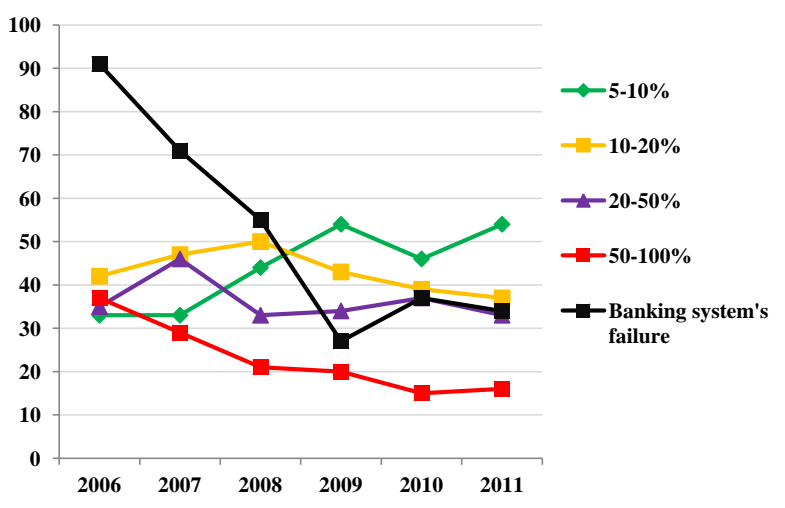

Figure 18: Number of banking systems grouped by the level of their capital losses with 100\% LGD (all banks exposed)

Source: own calculations based on the BIS and Bankscope data.

number of banks losing only $5-10 \%$ prevails. All this suggests that the system seems to become less vulnerable to cross-border contagion over time.

\subsection{Stress Testing with Only Large Banks as a Cushion}

In order to find out how contagion risk changes with capital buffers, we also conduct stress tests for the case when Tier 1 capital of only large banking institutions of a country is considered as a cushion to withstand cross-border shocks. Besides, small banks are less likely to engage in international transactions.

In general, this case is characterized by a somewhat higher speed of contagion and larger number of first-round and total defaults displayed in Figure 8 by dashed lines. However, as in the case with all banks, the number of failures first follows a downward trend and then from 2009 starts growing again. The simulations also reveal similar patterns for triggering countries and vulnerable banking systems (Figures 19 and 20 in the Appendix). However, Italy, Spain and Germany appear to generate cross- 
border implications for banking systems of other countries more often. Besides, while resilient to contagion for the case with all banks, banking systems of the US and Turkey appear to fail at least once with 100\% LGD.

Black boxes of Figures 11 - 16 show additional contagion effects that would occur with only large banks used as a cushion. For example, with 100\% LGD Italy could generate 13 and nine failures in 2008 and 2009, respectively, whereas it would not transmit contagion during these years in the case with all banks. Similarly, in 2007 and 2008 Spain would spill over contagion effects to 13 banking systems and would fail Portuguese banks in 2006-2008 already in the first round. Germany would trigger contagion in 2009 (nine defaults) and would lead to additional failures in 2011; whereas in 2011 the Netherlands would trigger Greek banks, which makes them even more directly exposed to cross-border contagion (five defaults in the first round).

Interestingly, the Italian banking system becomes extremely vulnerable to contagion in 2006, however, it was resilient with all banks exposed to shocks. Another interesting finding is that in 2009 a shock to the UK could trigger contagion to the US banks. Similarly, in 2006 a shock to the US would have cross-border implications also for the Turkish banking system and thus would fail all the network players after all rounds of contagion.

Naturally, the resulting additional failures are reflected in even more extensive capital losses of the system (Table 8 in the Appendix) and higher TCTF risk and vulnerability (Table 9 in the Appendix). Moreover, from Figure 21 in the Appendix it is seen that Italy, Spain and Germany generate much higher systemic impact. Considering the evolution of the number of affected banking systems grouped by their capital losses, Figure 22 in the Appendix demonstrates that between 2006 and 2008 there was no such a sharp drop in the number of failing banking systems as in the case with all banks as a cushion. Apart from that, we can say that the previously discovered patterns seem to hold.

\section{Concluding Remarks}

In this study we determined the evolution of potential systemic risks, contagion paths and systemic losses for the period of 2006-2011. The preliminary analysis of the data of eight countries (PIIGS, France, Germany and the UK) has shown that a single failure among PIIGS is not sufficient to trigger the default of a banking system of 
another country. However, multiple failures among PIIGS (especially combinations including Italy and/or Spain) could be more dangerous.

In order to account for all potential contagion paths, we ran the Furfine algorithm for an extended sample of 20 countries (Australia, Austria, Belgium, Canada, Finland, France, Germany, Greece, India, Ireland, Italy, Japan, the Netherlands, Portugal, Spain, Sweden, Switzerland, Turkey, the UK and the US). The results suggest that the magnitude of exposures, the expected LGD and the levels of Tier 1 capital are important determinants of the degree of contagion. A key finding is that the resilience to contagion tends to improve over the years. On average, the period between 2009 and 2011 is characterized by lower contagion risks and less frequent failures of banking systems than the period between 2006 and 2009. It could be due to the retrenchment of capital flows around the world and the recapitalization of banking systems and hence their increased absorption capacity in the wake of the global financial crisis. The simulation results confirmed the systemic importance of the US, the UK, France and Germany. These countries (especially the US and the UK) appear to trigger contagion to the highest number of banking systems and incur the largest systemic losses.

Regarding vulnerability levels, the results revealed that there exist considerable risks for Switzerland and Ireland as their banking systems default even with 25\% of LGD. At the same time, banking systems of the US, Turkey and Finland are completely immune to contagion effects occurring in the studied network. Besides, a shock to the US is capable of destroying the UK banking system already in the first round, whereas the UK would not lead to the failure of the US banking system even after all rounds of contagion.

Stress tests conducted with the use of data on Tier 1 capital of only large banks revealed similar patterns for triggering and vulnerable countries as well as contagion paths. Yet, this case is characterized by a somewhat higher speed of contagion, larger number of first-round and total defaults and, accordingly, even more extensive capital losses.

The approach employed in this paper has several advantages and allows to obtain results that are highly significant for. One advantage is that stress tests reveal systemically important players and the most vulnerable institutions in the network as well as track over time the changing capacity of the network to withstand shocks. Since we observed that the resilience of banking systems to contagion risks improved 
over the years, which coincided with the retrenchment of capital flows around the world and the recapitalization of banks in the wake of the global financial crisis, it seems that both better capitalized banking systems and reduced cross-border lending by banks decrease the danger of direct contagion from sovereigns to banks. However, in order to conclude which of these two factors is more important for banking systems' resilience, more research needs to be done. Besides, stress testing helps to identify not only direct, but also knock-on effects, which is particularly important in the face of an increased interconnectedness among countries. Another important advantage of this approach is that it allows to calculate potential systemic losses. On the basis of this information, policymakers could define the amounts and qualitative features of capital injections required for the overall system in order to reduce contagion risks.

Nevertheless, this study is limited in several ways. The first limitation is that our analysis is based on the BIS cross-border data on bank exposures aggregated at the country level. The lack of the bank-level data does not allow to reveal problems of particular banks. For instance, we found out that in 2010 and 2011 a shock to Greece and other PIIGS would not cause cross-border contagion to banking systems of other countries. However, this should not be taken to mean that there are no individual banks that could be at risk due to their significant exposures to borrowers in PIIGS. Second, given the difficulty in determining the appropriate level of LGD, we determined it exogenously and kept it constant over time and during all rounds of contagion. This could lead to an underestimation of contagion risks. Third, for the sake of simplicity we focused only on the credit channel of contagion and ignored other sources (e.g., liquidity risks). Fourth, we did not model probabilities of default conditional on the state of the economy and assumed that they are the same for all the countries in the study. Further research would help to address the above mentioned limitations. Finally, this approach is static in nature as it disregards the reactions of involved players. Since contagion can spread not only via direct interlinkages but can also be caused by the behavior of investors who act on fear, the usefulness of statistical market-based methods allowing to track changes in investors' perception of risk should not be underestimated. 


\section{Appendix}

Table 6: Number of defaults and rounds of contagion (all banks exposed)

\begin{tabular}{|c|c|c|c|c|c|c|c|}
\hline & LGD & 2006 & 2007 & 2008 & 2009 & 2010 & 2011 \\
\hline \multirow{4}{*}{ Ireland } & $100 \%$ & $12(1)-8 \mathrm{r}$ & $0(0)-1 \mathrm{r}$ & $0(0)-1 \mathrm{r}$ & $0(0)-1 \mathrm{r}$ & $0(0)-1 \mathrm{r}$ & $0(0)-1 \mathrm{r}$ \\
\hline & $75 \%$ & $0(0)-1 \mathrm{r}$ & $0(0)-1 \mathrm{r}$ & $0(0)-1 \mathrm{r}$ & $0(0)-1 \mathrm{r}$ & $0(0)-1 \mathrm{r}$ & $0(0)-1 \mathrm{r}$ \\
\hline & $50 \%$ & $0(0)-1 \mathrm{r}$ & $0(0)-1 \mathrm{r}$ & $0(0)-1 \mathrm{r}$ & $0(0)-1 \mathrm{r}$ & $0(0)-1 \mathrm{r}$ & $0(0)-1 \mathrm{r}$ \\
\hline & $25 \%$ & $0(0)-1 \mathrm{r}$ & $0(0)-1 \mathrm{r}$ & $0(0)-1 \mathrm{r}$ & $0(0)-1 \mathrm{r}$ & $0(0)-1 \mathrm{r}$ & $0(0)-1 \mathrm{r}$ \\
\hline \multirow{4}{*}{ Italy } & $100 \%$ & $13(4)-5 r$ & $13(1)-5 \mathrm{r}$ & $0(0)-1 \mathrm{r}$ & $0(0)-1 \mathrm{r}$ & $0(0)-1 \mathrm{r}$ & $0(0)-1 \mathrm{r}$ \\
\hline & $75 \%$ & $12(1)-6 \mathrm{r}$ & $12(1)-6 \mathrm{r}$ & $0(0)-1 \mathrm{r}$ & $0(0)-1 \mathrm{r}$ & $0(0)-1 \mathrm{r}$ & $0(0)-1 \mathrm{r}$ \\
\hline & $50 \%$ & $0(0)-1 \mathrm{r}$ & $0(0)-1 \mathrm{r}$ & $0(0)-1 \mathrm{r}$ & $0(0)-1 \mathrm{r}$ & $0(0)-1 r$ & $0(0)-1 \mathrm{r}$ \\
\hline & $25 \%$ & $0(0)-1 \mathrm{r}$ & $0(0)-1 \mathrm{r}$ & $0(0)-1 \mathrm{r}$ & $0(0)-1 \mathrm{r}$ & $0(0)-1 \mathrm{r}$ & $0(0)-1 \mathrm{r}$ \\
\hline \multirow{4}{*}{ Spain } & $100 \%$ & $12(1)-6 r$ & $0(0)-1 \mathrm{r}$ & $0(0)-1 \mathrm{r}$ & $0(0)-1 \mathrm{r}$ & $0(0)-1 \mathrm{r}$ & $0(0)-1 \mathrm{r}$ \\
\hline & $75 \%$ & $0(0)-1 \mathrm{r}$ & $0(0)-1 \mathrm{r}$ & $0(0)-1 \mathrm{r}$ & $0(0)-1 \mathrm{r}$ & $0(0)-1 \mathrm{r}$ & $0(0)-1 \mathrm{r}$ \\
\hline & $50 \%$ & $0(0)-1 \mathrm{r}$ & $0(0)-1 \mathrm{r}$ & $0(0)-1 \mathrm{r}$ & $0(0)-1 \mathrm{r}$ & $0(0)-1 \mathrm{r}$ & $0(0)-1 \mathrm{r}$ \\
\hline & $25 \%$ & $0(0)-1 \mathrm{r}$ & $0(0)-1 \mathrm{r}$ & $0(0)-1 \mathrm{r}$ & $0(0)-1 \mathrm{r}$ & $0(0)-1 \mathrm{r}$ & $0(0)-1 \mathrm{r}$ \\
\hline \multirow{4}{*}{ France } & $100 \%$ & $12(2)-6 \mathrm{r}$ & $13(2)-6 \mathrm{r}$ & $13(1)-8 r$ & $0(0)-1 \mathrm{r}$ & $0(0)-1 \mathrm{r}$ & $0(0)-1 \mathrm{r}$ \\
\hline & $75 \%$ & $11(1)-7 \mathrm{r}$ & $12(1)-7 \mathrm{r}$ & $2(1)-3 r$ & $0(0)-1 \mathrm{r}$ & $0(0)-1 \mathrm{r}$ & $0(0)-1 \mathrm{r}$ \\
\hline & $50 \%$ & $1(1)-2 \mathrm{r}$ & $0(0)-1 \mathrm{r}$ & $0(0)-1 \mathrm{r}$ & $0(0)-1 \mathrm{r}$ & $0(0)-1 \mathrm{r}$ & $0(0)-1 \mathrm{r}$ \\
\hline & $25 \%$ & $0(0)-1 \mathrm{r}$ & $0(0)-1 \mathrm{r}$ & $0(0)-1 \mathrm{r}$ & $0(0)-1 \mathrm{r}$ & $0(0)-1 \mathrm{r}$ & $0(0)-1 \mathrm{r}$ \\
\hline \multirow{4}{*}{ Germany } & $100 \%$ & $12(5)-5 \mathrm{r}$ & $13(6)-5 \mathrm{r}$ & $13(3)-6 r$ & $0(0)-1 \mathrm{r}$ & $8(2)-6 r$ & $2(1)-3 r$ \\
\hline & $75 \%$ & $11(4)-5 \mathrm{r}$ & $12(2)-6 \mathrm{r}$ & $0(0)-1 \mathrm{r}$ & $0(0)-1 \mathrm{r}$ & $1(1)-2 \mathrm{r}$ & $0(0)-1 \mathrm{r}$ \\
\hline & $50 \%$ & $3(1)-4 r$ & $0(0)-1 \mathrm{r}$ & $0(0)-1 \mathrm{r}$ & $0(0)-1 \mathrm{r}$ & $0(0)-1 \mathrm{r}$ & $0(0)-1 \mathrm{r}$ \\
\hline & $25 \%$ & $0(0)-1 \mathrm{r}$ & $0(0)-1 \mathrm{r}$ & $0(0)-1 \mathrm{r}$ & $0(0)-1 \mathrm{r}$ & $0(0)-1 \mathrm{r}$ & $0(0)-1 \mathrm{r}$ \\
\hline \multirow{4}{*}{ UK } & $100 \%$ & $12(8)-4 r$ & $13(8)-4 \mathrm{r}$ & $13(7)-4 \mathrm{r}$ & $12(4)-4 \mathrm{r}$ & $13(3)-5 \mathrm{r}$ & $14(4)-5 r$ \\
\hline & $75 \%$ & $11(6)-3 \mathrm{r}$ & $12(6)-3 r$ & $12(4)-4 r$ & $12(2)-6 \mathrm{r}$ & $10(1)-7 \mathrm{r}$ & $3(2)-3 r$ \\
\hline & $50 \%$ & $10(5)-4 \mathrm{r}$ & $11(5)-5 \mathrm{r}$ & $1(1)-2 \mathrm{r}$ & $1(1)-2 \mathrm{r}$ & $1(1)-2 \mathrm{r}$ & $2(2)-2 r$ \\
\hline & $25 \%$ & $5(1)-5 r$ & $1(1)-2 r$ & $0(0)-1 \mathrm{r}$ & $0(0)-1 \mathrm{r}$ & $0(0)-1 \mathrm{r}$ & $0(0)-1 \mathrm{r}$ \\
\hline \multirow{6}{*}{ US } & $100 \%$ & $14(8)-3 r$ & $14(8)-3 r$ & $14(8)-3 r$ & $14(7)-3 \mathrm{r}$ & $15(5)-4 \mathrm{r}$ & $16(7)-4 r$ \\
\hline & $75 \%$ & $14(8)-4 \mathrm{r}$ & $14(6)-3 r$ & $14(6)-3 \mathrm{r}$ & $14(3)-5 \mathrm{r}$ & $15(3)-6 \mathrm{r}$ & $15(3)-5 r$ \\
\hline & $50 \%$ & $13(6)-4 \mathrm{r}$ & $14(4)-5 \mathrm{r}$ & $13(2)-5 r$ & $1(1)-2 \mathrm{r}$ & $2(2)-2 r$ & $2(2)-2 \mathrm{r}$ \\
\hline & $25 \%$ & $6(2)-4 \mathrm{r}$ & $1(1)-2 r$ & $1(1)-2 \mathrm{r}$ & $1(1)-2 \mathrm{r}$ & $1(1)-2 \mathrm{r}$ & $1(1)-2 r$ \\
\hline & $100 \%$ & $0(0)-1 \mathrm{r}$ & $1(1)-2 r$ & $1(1)-2 \mathrm{r}$ & $0(0)-1 \mathrm{r}$ & $0(0)-1 \mathrm{r}$ & $0(0)-1 \mathrm{r}$ \\
\hline & $75 \%$ & $0(0)-1 \mathrm{r}$ & $0(0)-1 r$ & $0(0)-1 \mathrm{r}$ & $0(0)-1 \mathrm{r}$ & $0(0)-1 \mathrm{r}$ & $0(0)-1 \mathrm{r}$ \\
\hline
\end{tabular}


Table 6: continued

\begin{tabular}{|c|c|c|c|c|c|c|c|}
\hline & LGD & 2006 & 2007 & 2008 & 2009 & 2010 & 2011 \\
\hline & $50 \%$ & $0(0)-1 \mathrm{r}$ & $0(0)-1 \mathrm{r}$ & $0(0)-1 \mathrm{r}$ & $0(0)-1 \mathrm{r}$ & $0(0)-1 \mathrm{r}$ & $0(0)-1 \mathrm{r}$ \\
\hline & $25 \%$ & $0(0)-1 \mathrm{r}$ & $0(0)-1 \mathrm{r}$ & $0(0)-1 \mathrm{r}$ & $0(0)-1 \mathrm{r}$ & $0(0)-1 \mathrm{r}$ & $0(0)-1 \mathrm{r}$ \\
\hline \multirow{4}{*}{ Finland } & $100 \%$ & $1(1)-2 \mathrm{r}$ & $1(1)-2 r$ & $1(1)-2 \mathrm{r}$ & $1(1)-2 \mathrm{r}$ & $1(1)-2 \mathrm{r}$ & $1(1)-2 \mathrm{r}$ \\
\hline & $75 \%$ & $1(1)-2 \mathrm{r}$ & $1(1)-2 r$ & $1(1)-2 \mathrm{r}$ & $0(0)-1 \mathrm{r}$ & $0(0)-1 \mathrm{r}$ & $1(1)-2 \mathrm{r}$ \\
\hline & $50 \%$ & $0(0)-1 \mathrm{r}$ & $0(0)-1 \mathrm{r}$ & $0(0)-1 \mathrm{r}$ & $0(0)-1 \mathrm{r}$ & $0(0)-1 \mathrm{r}$ & $0(0)-1 \mathrm{r}$ \\
\hline & $25 \%$ & $0(0)-1 \mathrm{r}$ & $0(0)-1 \mathrm{r}$ & $0(0)-1 \mathrm{r}$ & $0(0)-1 \mathrm{r}$ & $0(0)-1 \mathrm{r}$ & $0(0)-1 \mathrm{r}$ \\
\hline \multirow{4}{*}{ Netherlands } & $100 \%$ & $1(1)-2 \mathrm{r}$ & $1(1)-2 \mathrm{r}$ & $0(0)-1 \mathrm{r}$ & $0(0)-1 \mathrm{r}$ & $0(0)-1 \mathrm{r}$ & $0(0)-1 \mathrm{r}$ \\
\hline & $75 \%$ & $1(1)-2 r$ & $1(1)-2 \mathrm{r}$ & $0(0)-1 \mathrm{r}$ & $0(0)-1 \mathrm{r}$ & $0(0)-1 \mathrm{r}$ & $0(0)-1 \mathrm{r}$ \\
\hline & $50 \%$ & $1(1)-2 r$ & $0(0)-1 \mathrm{r}$ & $0(0)-1 \mathrm{r}$ & $0(0)-1 \mathrm{r}$ & $0(0)-1 \mathrm{r}$ & $0(0)-1 \mathrm{r}$ \\
\hline & $25 \%$ & $0(0)-1 \mathrm{r}$ & $0(0)-1 \mathrm{r}$ & $0(0)-1 \mathrm{r}$ & $0(0)-1 \mathrm{r}$ & $0(0)-1 \mathrm{r}$ & $0(0)-1 \mathrm{r}$ \\
\hline \multirow{4}{*}{ Japan } & $100 \%$ & $1(1)-2 r$ & $1(1)-2 r$ & $0(0)-1 \mathrm{r}$ & $0(0)-1 \mathrm{r}$ & $0(0)-1 \mathrm{r}$ & $0(0)-1 \mathrm{r}$ \\
\hline & $75 \%$ & $1(1)-2 r$ & $1(1)-2 \mathrm{r}$ & $0(0)-1 \mathrm{r}$ & $0(0)-1 \mathrm{r}$ & $0(0)-1 \mathrm{r}$ & $0(0)-1 \mathrm{r}$ \\
\hline & $50 \%$ & $0(0)-1 \mathrm{r}$ & $0(0)-1 \mathrm{r}$ & $0(0)-1 \mathrm{r}$ & $0(0)-1 \mathrm{r}$ & $0(0)-1 \mathrm{r}$ & $0(0)-1 \mathrm{r}$ \\
\hline & $25 \%$ & $0(0)-1 \mathrm{r}$ & $0(0)-1 \mathrm{r}$ & $0(0)-1 \mathrm{r}$ & $0(0)-1 \mathrm{r}$ & $0(0)-1 \mathrm{r}$ & $0(0)-1 \mathrm{r}$ \\
\hline \multirow{4}{*}{ Turkey } & $100 \%$ & $1(1)-2 \mathrm{r}$ & $1(1)-2 r$ & $0(0)-1 \mathrm{r}$ & $0(0)-1 \mathrm{r}$ & $0(0)-1 \mathrm{r}$ & $1(1)-2 \mathrm{r}$ \\
\hline & $75 \%$ & $0(0)-1 \mathrm{r}$ & $0(0)-1 \mathrm{r}$ & $0(0)-1 \mathrm{r}$ & $0(0)-1 \mathrm{r}$ & $0(0)-1 \mathrm{r}$ & $1(1)-2 \mathrm{r}$ \\
\hline & $50 \%$ & $0(0)-1 \mathrm{r}$ & $0(0)-1 \mathrm{r}$ & $0(0)-1 \mathrm{r}$ & $0(0)-1 \mathrm{r}$ & $0(0)-1 \mathrm{r}$ & $1(1)-2 \mathrm{r}$ \\
\hline & $25 \%$ & $0(0)-1 \mathrm{r}$ & $0(0)-1 \mathrm{r}$ & $0(0)-1 \mathrm{r}$ & $0(0)-1 \mathrm{r}$ & $0(0)-1 \mathrm{r}$ & $1(1)-2 r$ \\
\hline \multirow{4}{*}{ Total defaults } & $100 \%$ & $91(33)$ & $71(30)$ & $55(21)$ & $27(12)$ & $37(11)$ & $34(14)$ \\
\hline & $75 \%$ & $62(23)$ & $65(19)$ & $29(12)$ & $26(5)$ & $26(5)$ & $20(7)$ \\
\hline & $50 \%$ & $28(14)$ & $25(9)$ & $14(3)$ & $2(2)$ & $3(3)$ & $5(5)$ \\
\hline & $25 \%$ & $11(3)$ & $2(2)$ & $1(1)$ & $1(1)$ & $1(1)$ & $2(2)$ \\
\hline
\end{tabular}

Note: the number of first-round defaults is shown in brackets.

Source: own calculations based on the BIS and Bankscope data. 


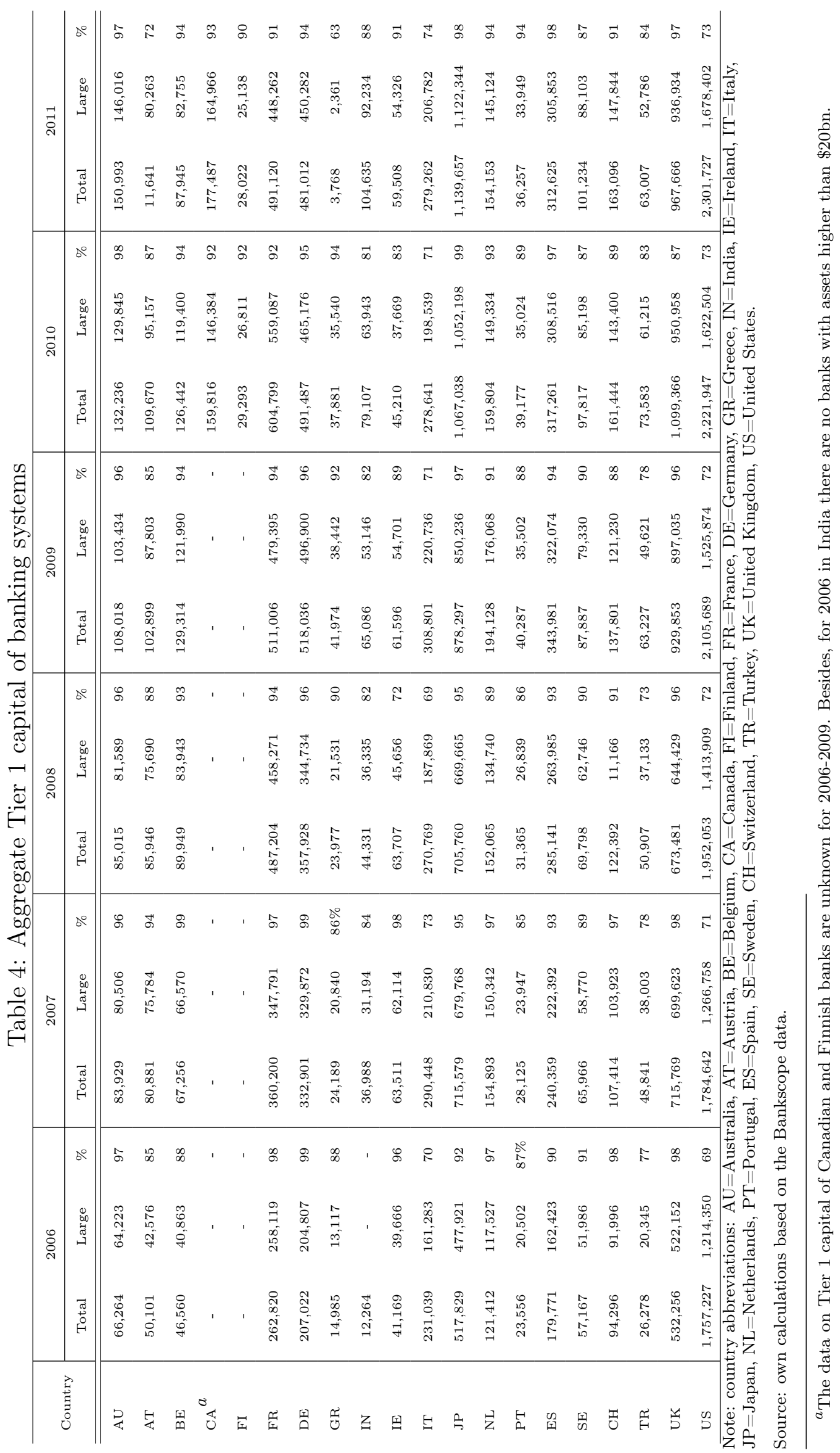


Table 5: Ratio of total (largest) claims to Tier 1 capital for PIIGS, France, Germany and the $\underline{\mathrm{UK}}$

\begin{tabular}{|c|c|c|c|c|c|c|c|}
\hline & 2006 & 2007 & 2008 & 2009 & 2010 & 2011 & Average \\
\hline \multicolumn{8}{|l|}{ Greece } \\
\hline Total claims/Tier 1 capital & 4.0 & 3.8 & 4.0 & 3.5 & 3.7 & 33.6 & 8.8 \\
\hline Largest claim/Tier 1 capital & 1.1 & 1.2 & 0.8 & 0.6 & 0.8 & 7.4 & 2.0 \\
\hline \multicolumn{8}{|l|}{ Ireland } \\
\hline Total claims/Tier 1 capital & 14.4 & 11.7 & 10.6 & 10.0 & 9.1 & 3.1 & 9.8 \\
\hline Largest claim/Tier 1 capital & 4.5 & 4.1 & 3.5 & 3.6 & 3.5 & 2.3 & 3.6 \\
\hline \multicolumn{8}{|l|}{ Italy } \\
\hline Total claims/Tier 1 capital & 1.5 & 3.8 & 3.8 & 3.1 & 3.2 & 3.0 & 3.1 \\
\hline Largest claim/Tier 1 capital & 0.2 & 1.3 & 1.2 & 0.9 & 0.9 & 0.8 & 0.9 \\
\hline \multicolumn{8}{|l|}{ Portugal } \\
\hline Total claims/Tier 1 capital & 5.4 & 5.1 & 4.6 & 3.9 & 3.6 & 3.3 & 4.3 \\
\hline Largest claim/Tier 1 capital & 0.9 & 1.0 & 0.9 & 0.7 & 0.7 & 0.6 & 0.8 \\
\hline \multicolumn{8}{|l|}{ Spain } \\
\hline Total claims/Tier 1 capital & 5.4 & 5.1 & 4.1 & 4.0 & 4.3 & 4.5 & 4.5 \\
\hline Largest claim/Tier 1 capital & 1.7 & 1.4 & 1.2 & 1.2 & 1.3 & 1.3 & 1.4 \\
\hline \multicolumn{8}{|l|}{ France } \\
\hline Total claims/Tier 1 capital & 9.6 & 9.9 & 7.3 & 7.2 & 5.1 & 5.6 & 7.4 \\
\hline Largest claim/Tier 1 capital & 2.6 & 1.9 & 1.6 & 1.1 & 0.9 & 1.1 & 1.5 \\
\hline \multicolumn{8}{|l|}{ Germany } \\
\hline Total claims/Tier 1 capital & 16.2 & 12.8 & 9.9 & 6.3 & 6.0 & 5.7 & 9.5 \\
\hline Largest claim/Tier 1 capital & 3.4 & 2.6 & 1.8 & 1.0 & 1.0 & 1.1 & 1.8 \\
\hline \multicolumn{8}{|l|}{ UK } \\
\hline Total claims/Tier 1 capital & 6.1 & 5.6 & 5.5 & 3.9 & 3.6 & 4.1 & 4.8 \\
\hline Largest claim/Tier 1 capital & 2.1 & 1.7 & 1.8 & 1.2 & 1.0 & 1.1 & 1.5 \\
\hline
\end{tabular}

Source: own calculations based on the BIS and Bankscope data.

Table 7: Number of defaults and rounds of contagion (only large banks exposed)

\begin{tabular}{cccccccc}
\hline & LGD & $\mathbf{2 0 0 6}$ & $\mathbf{2 0 0 7}$ & $\mathbf{2 0 0 8}$ & $\mathbf{2 0 0 9}$ & $\mathbf{2 0 1 0}$ & $\mathbf{2 0 1 1}$ \\
\hline \hline \multirow{5}{*}{ Ireland } & $100 \%$ & $13(1)-8 \mathrm{r}$ & $0(0)-1 \mathrm{r}$ & $0(0)-1 \mathrm{r}$ & $0(0)-1 \mathrm{r}$ & $0(0)-1 \mathrm{r}$ & $0(0)-1 \mathrm{r}$ \\
& $75 \%$ & $1(1)-2 \mathrm{r}$ & $0(0)-1 \mathrm{r}$ & $0(0)-1 \mathrm{r}$ & $0(0)-1 \mathrm{r}$ & $0(0)-1 \mathrm{r}$ & $0(0)-1 \mathrm{r}$ \\
& $50 \%$ & $0(0)-1 \mathrm{r}$ & $0(0)-1 \mathrm{r}$ & $0(0)-1 \mathrm{r}$ & $0(0)-1 \mathrm{r}$ & $0(0)-1 \mathrm{r}$ & $0(0)-1 \mathrm{r}$ \\
& $25 \%$ & $0(0)-1 \mathrm{r}$ & $0(0)-1 \mathrm{r}$ & $0(0)-1 \mathrm{r}$ & $0(0)-1 \mathrm{r}$ & $0(0)-1 \mathrm{r}$ & $0(0)-1 \mathrm{r}$ \\
\hline \multirow{5}{*}{ Italy } & $100 \%$ & $13(4)-\mathrm{r}$ & $13(1)-5 \mathrm{r}$ & $13(2)-6 \mathrm{r}$ & $9(1)-6 \mathrm{r}$ & $0(0)-1 \mathrm{r}$ & $0(0)-1 \mathrm{r}$ \\
& $75 \%$ & $12(1)-6 \mathrm{r}$ & $12(1)-6 \mathrm{r}$ & $0(0)-1 \mathrm{r}$ & $0(0)-1 \mathrm{r}$ & $0(0)-1 \mathrm{r}$ & $0(0)-1 \mathrm{r}$ \\
& $50 \%$ & $0(0)-1 \mathrm{r}$ & $0(0)-1 \mathrm{r}$ & $0(0)-1 \mathrm{r}$ & $0(0)-1 \mathrm{r}$ & $0(0)-1 \mathrm{r}$ & $0(0)-1 \mathrm{r}$ \\
& $25 \%$ & $0(0)-1 \mathrm{r}$ & $0(0)-1 \mathrm{r}$ & $0(0)-1 \mathrm{r}$ & $0(0)-1 \mathrm{r}$ & $0(0)-1 \mathrm{r}$ & $0(0)-1 \mathrm{r}$ \\
\hline
\end{tabular}


Table 7: continued

\begin{tabular}{|c|c|c|c|c|c|c|c|}
\hline & LGD & 2006 & 2007 & 2008 & 2009 & 2010 & 2011 \\
\hline \multirow{4}{*}{ Spain } & $100 \%$ & $13(2)-5 \mathrm{r}$ & $13(1)-6 r$ & $13(1)-7 \mathrm{r}$ & $0(0)-1 \mathrm{r}$ & $0(0)-1 \mathrm{r}$ & $0(0)-1 \mathrm{r}$ \\
\hline & $75 \%$ & $0(0)-1 \mathrm{r}$ & $0(0)-1 \mathrm{r}$ & $0(0)-1 \mathrm{r}$ & $0(0)-1 \mathrm{r}$ & $0(0)-1 \mathrm{r}$ & $0(0)-1 \mathrm{r}$ \\
\hline & $50 \%$ & $0(0)-1 \mathrm{r}$ & $0(0)-1 \mathrm{r}$ & $0(0)-1 \mathrm{r}$ & $0(0)-1 \mathrm{r}$ & $0(0)-1 \mathrm{r}$ & $0(0)-1 \mathrm{r}$ \\
\hline & $25 \%$ & $0(0)-1 \mathrm{r}$ & $0(0)-1 \mathrm{r}$ & $0(0)-1 \mathrm{r}$ & $0(0)-1 \mathrm{r}$ & $0(0)-1 \mathrm{r}$ & $0(0)-1 \mathrm{r}$ \\
\hline \multirow{4}{*}{ France } & $100 \%$ & $13(2)-6 r$ & $13(2)-5 r$ & $13(1)-8 r$ & $0(0)-1 \mathrm{r}$ & $0(0)-1 \mathrm{r}$ & $0(0)-1 \mathrm{r}$ \\
\hline & $75 \%$ & $11(1)-7 \mathrm{r}$ & $12(1)-7 \mathrm{r}$ & $2(1)-3 r$ & $0(0)-1 \mathrm{r}$ & $0(0)-1 \mathrm{r}$ & $0(0)-1 \mathrm{r}$ \\
\hline & $50 \%$ & $1(1)-2 \mathrm{r}$ & $0(0)-1 \mathrm{r}$ & $0(0)-1 \mathrm{r}$ & $0(0)-1 \mathrm{r}$ & $0(0)-1 \mathrm{r}$ & $0(0)-1 \mathrm{r}$ \\
\hline & $25 \%$ & $0(0)-1 \mathrm{r}$ & $0(0)-1 \mathrm{r}$ & $0(0)-1 \mathrm{r}$ & $0(0)-1 \mathrm{r}$ & $0(0)-1 \mathrm{r}$ & $0(0)-1 \mathrm{r}$ \\
\hline \multirow{4}{*}{ Germany } & $100 \%$ & $13(6)-5 \mathrm{r}$ & $13(6)-4 r$ & $13(5)-5 r$ & $9(2)-4 \mathrm{r}$ & $8(3)-4 r$ & $8(3)-5 r$ \\
\hline & $75 \%$ & $11(4)-5 \mathrm{r}$ & $12(4)-5 r$ & $12(1)-6 r$ & $0(0)-1 \mathrm{r}$ & $5(1)-5 \mathrm{r}$ & $0(0)-1 \mathrm{r}$ \\
\hline & $50 \%$ & $4(1)-5 r$ & $0(0)-1 \mathrm{r}$ & $0(0)-1 \mathrm{r}$ & $0(0)-1 \mathrm{r}$ & $0(0)-1 \mathrm{r}$ & $0(0)-1 \mathrm{r}$ \\
\hline & $25 \%$ & $0(0)-1 \mathrm{r}$ & $0(0)-1 \mathrm{r}$ & $0(0)-1 \mathrm{r}$ & $0(0)-1 \mathrm{r}$ & $0(0)-1 \mathrm{r}$ & $0(0)-1 \mathrm{r}$ \\
\hline \multirow{4}{*}{ UK } & $100 \%$ & $13(8)-4 \mathrm{r}$ & $13(8)-3 r$ & $13(7)-4 \mathrm{r}$ & $14(5)-3 \mathrm{r}$ & $13(4)-4 \mathrm{r}$ & $14(5)-4 r$ \\
\hline & $75 \%$ & $11(6)-3 \mathrm{r}$ & $12(6)-3 \mathrm{r}$ & $12(5)-4 \mathrm{r}$ & $12(2)-5 \mathrm{r}$ & $11(2)-5 \mathrm{r}$ & $12(3)-5 r$ \\
\hline & $50 \%$ & $10(5)-3 r$ & $11(5)-4 \mathrm{r}$ & $10(1)-7 \mathrm{r}$ & $1(1)-2 \mathrm{r}$ & $1(1)-2 \mathrm{r}$ & $2(2)-2 r$ \\
\hline & $25 \%$ & $5(2)-4 \mathrm{r}$ & $1(1)-2 \mathrm{r}$ & $1(1)-2 \mathrm{r}$ & $1(1)-2 \mathrm{r}$ & $1(1)-2 \mathrm{r}$ & $1(1)-2 r$ \\
\hline \multirow{4}{*}{ US } & $100 \%$ & $16(8)-4 r$ & $14(8)-3 r$ & $14(8)-3 r$ & $14(7)-3 \mathrm{r}$ & $15(7)-3 \mathrm{r}$ & $16(9)-3 r$ \\
\hline & $75 \%$ & $13(8)-3 r$ & $14(6)-3 r$ & $14(8)-3 r$ & $14(3)-4 \mathrm{r}$ & $15(4)-5 \mathrm{r}$ & $16(3)-5 r$ \\
\hline & $50 \%$ & $13(6)-3 \mathrm{r}$ & $14(4)-4 \mathrm{r}$ & $14(3)-5 r$ & $1(1)-2 \mathrm{r}$ & $4(2)-4 \mathrm{r}$ & $4(2)-4 r$ \\
\hline & $25 \%$ & $6(2)-4 \mathrm{r}$ & $1(1)-2 r$ & $1(1)-2 r$ & $1(1)-2 \mathrm{r}$ & $1(1)-2 r$ & $1(1)-2 \mathrm{r}$ \\
\hline \multirow{4}{*}{ Belgium } & $100 \%$ & $0(0)-1 \mathrm{r}$ & $1(1)-2 \mathrm{r}$ & $1(1)-2 r$ & $0(0)-1 \mathrm{r}$ & $0(0)-1 \mathrm{r}$ & $0(0)-1 \mathrm{r}$ \\
\hline & $75 \%$ & $0(0)-1 \mathrm{r}$ & $0(0)-1 \mathrm{r}$ & $0(0)-1 \mathrm{r}$ & $0(0)-1 \mathrm{r}$ & $0(0)-1 \mathrm{r}$ & $0(0)-1 \mathrm{r}$ \\
\hline & $50 \%$ & $0(0)-1 \mathrm{r}$ & $0(0)-1 \mathrm{r}$ & $0(0)-1 \mathrm{r}$ & $0(0)-1 \mathrm{r}$ & $0(0)-1 \mathrm{r}$ & $0(0)-1 \mathrm{r}$ \\
\hline & $25 \%$ & $0(0)-1 \mathrm{r}$ & $0(0)-1 \mathrm{r}$ & $0(0)-1 \mathrm{r}$ & $0(0)-1 \mathrm{r}$ & $0(0)-1 \mathrm{r}$ & $0(0)-1 \mathrm{r}$ \\
\hline \multirow{4}{*}{ Finland } & $100 \%$ & $1(1)-2 \mathrm{r}$ & $1(1)-2 \mathrm{r}$ & $1(1)-2 \mathrm{r}$ & $1(1)-2 \mathrm{r}$ & $1(1)-2 r$ & $1(1)-2 r$ \\
\hline & $75 \%$ & $1(1)-2 \mathrm{r}$ & $1(1)-2 \mathrm{r}$ & $1(1)-2 r$ & $1(1)-2 \mathrm{r}$ & $1(1)-2 \mathrm{r}$ & $1(1)-2 \mathrm{r}$ \\
\hline & $50 \%$ & $0(0)-1 \mathrm{r}$ & $0(0)-1 \mathrm{r}$ & $0(0)-1 \mathrm{r}$ & $0(0)-1 \mathrm{r}$ & $0(0)-1 \mathrm{r}$ & $0(0)-1 \mathrm{r}$ \\
\hline & $25 \%$ & $0(0)-1 \mathrm{r}$ & $0(0)-1 \mathrm{r}$ & $0(0)-1 \mathrm{r}$ & $0(0)-1 \mathrm{r}$ & $0(0)-1 \mathrm{r}$ & $0(0)-1 \mathrm{r}$ \\
\hline \multirow{4}{*}{ Netherlands } & $100 \%$ & $1(1)-2 \mathrm{r}$ & $1(1)-2 \mathrm{r}$ & $1(1)-2 \mathrm{r}$ & $0(0)-1 \mathrm{r}$ & $0(0)-1 \mathrm{r}$ & $1(1)-2 \mathrm{r}$ \\
\hline & $75 \%$ & $1(1)-2 r$ & $1(1)-2 \mathrm{r}$ & $0(0)-1 \mathrm{r}$ & $0(0)-1 \mathrm{r}$ & $0(0)-1 \mathrm{r}$ & $1(1)-2 r$ \\
\hline & $50 \%$ & $1(1)-2 \mathrm{r}$ & $1(1)-2 r$ & $0(0)-1 \mathrm{r}$ & $0(0)-1 \mathrm{r}$ & $0(0)-1 \mathrm{r}$ & $0(0)-1 \mathrm{r}$ \\
\hline & $25 \%$ & $1(1)-2 \mathrm{r}$ & $0(0)-1 \mathrm{r}$ & $0(0)-1 \mathrm{r}$ & $0(0)-1 \mathrm{r}$ & $0(0)-1 \mathrm{r}$ & $0(0)-1 \mathrm{r}$ \\
\hline
\end{tabular}


Table 7: continued

\begin{tabular}{cccccccc}
\hline & LGD & $\mathbf{2 0 0 6}$ & $\mathbf{2 0 0 7}$ & $\mathbf{2 0 0 8}$ & $\mathbf{2 0 0 9}$ & $\mathbf{2 0 1 0}$ & $\mathbf{2 0 1 1}$ \\
\hline \multirow{5}{*}{ Japan } & $100 \%$ & $1(1)-2 \mathrm{r}$ & $1(1)-2 \mathrm{r}$ & $1(1)-2 \mathrm{r}$ & $0(0)-1 \mathrm{r}$ & $0(0)-1 \mathrm{r}$ & $0(0)-1 \mathrm{r}$ \\
& $75 \%$ & $1(1)-2 \mathrm{r}$ & $1(1)-2 \mathrm{r}$ & $0(0)-1 \mathrm{r}$ & $0(0)-1 \mathrm{r}$ & $0(0)-1 \mathrm{r}$ & $0(0)-1 \mathrm{r}$ \\
& $50 \%$ & $0(0)-1 \mathrm{r}$ & $0(0)-1 \mathrm{r}$ & $0(0)-1 \mathrm{r}$ & $0(0)-1 \mathrm{r}$ & $0(0)-1 \mathrm{r}$ & $0(0)-1 \mathrm{r}$ \\
& $25 \%$ & $0(0)-1 \mathrm{r}$ & $0(0)-1 \mathrm{r}$ & $0(0)-1 \mathrm{r}$ & $0(0)-1 \mathrm{r}$ & $0(0)-1 \mathrm{r}$ & $0(0)-1 \mathrm{r}$ \\
\hline \multirow{5}{*}{ Turkey } & $100 \%$ & $1(1)-2 \mathrm{r}$ & $1(1)-2 \mathrm{r}$ & $0(0)-1 \mathrm{r}$ & $0(0)-1 \mathrm{r}$ & $0(0)-1 \mathrm{r}$ & $1(1)-2 \mathrm{r}$ \\
& $75 \%$ & $0(0)-1 \mathrm{r}$ & $1(1)-2 \mathrm{r}$ & $0(0)-1 \mathrm{r}$ & $0(0)-1 \mathrm{r}$ & $0(0)-1 \mathrm{r}$ & $1(1)-2 \mathrm{r}$ \\
& $50 \%$ & $0(0)-1 \mathrm{r}$ & $0(0)-1 \mathrm{r}$ & $0(0)-1 \mathrm{r}$ & $0(0)-1 \mathrm{r}$ & $0(0)-1 \mathrm{r}$ & $1(1)-2 \mathrm{r}$ \\
& $25 \%$ & $0(0)-1 \mathrm{r}$ & $0(0)-1 \mathrm{r}$ & $0(0)-1 \mathrm{r}$ & $0(0)-1 \mathrm{r}$ & $0(0)-1 \mathrm{r}$ & $1(1)-2 \mathrm{r}$ \\
\hline \multirow{5}{*}{ Total defaults } & $100 \%$ & $98(35)$ & $84(31)$ & $83(28)$ & $47(16)$ & $37(15)$ & $41(20)$ \\
& $75 \%$ & $62(24)$ & $66(22)$ & $41(16)$ & $267(6)$ & $32(8)$ & $31(9)$ \\
& $50 \%$ & $29(14)$ & $26(10)$ & $24(4)$ & $2(2)$ & $5(3)$ & $7(5)$ \\
& $25 \%$ & $12(5)$ & $2(2)$ & $2(2)$ & $2(2)$ & $2(2)$ & $3(3)$ \\
\hline
\end{tabular}

Note: the number of first-round defaults is shown in brackets.

Source: own calculations based on the BIS and Bankscope data. 


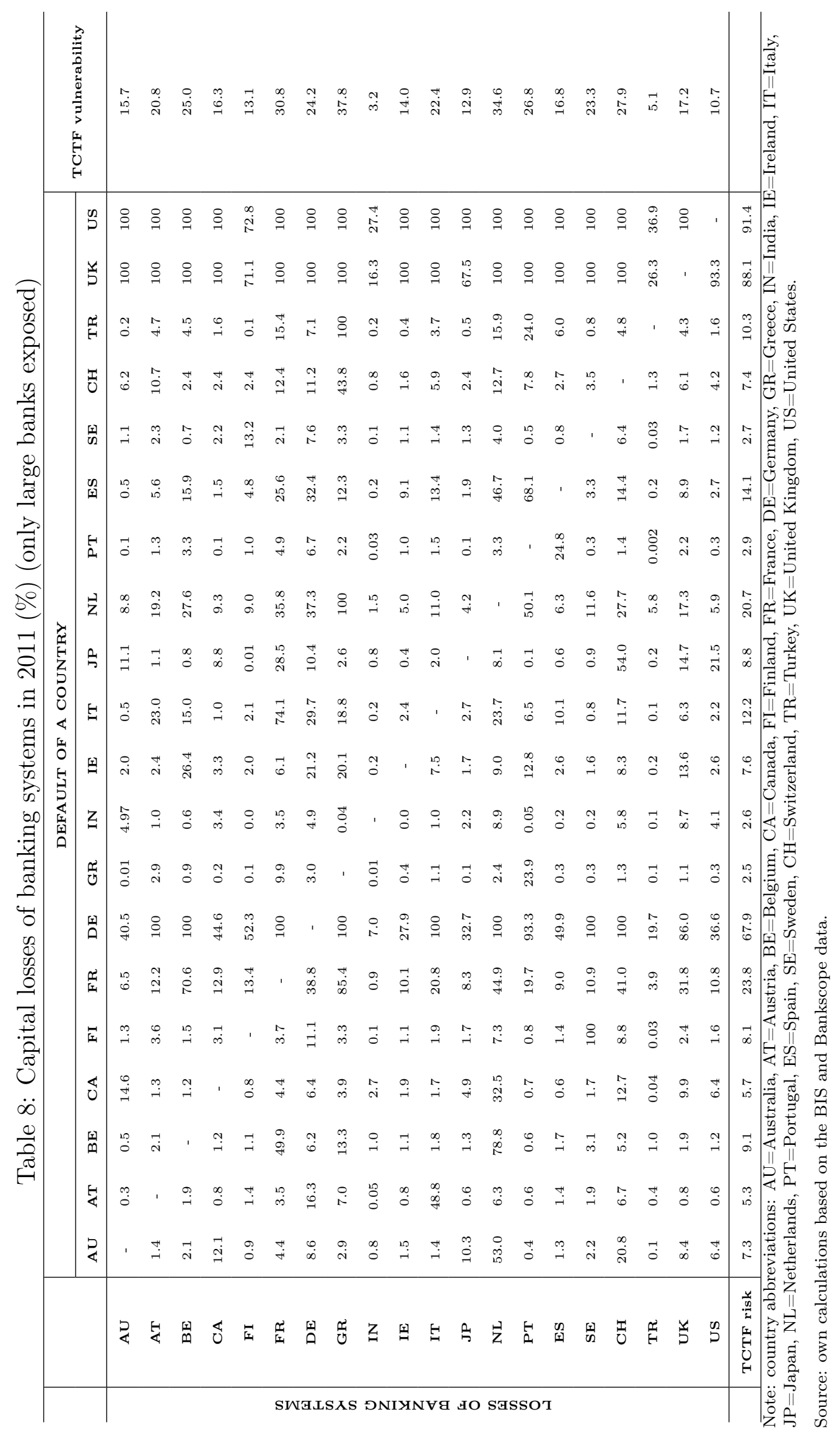




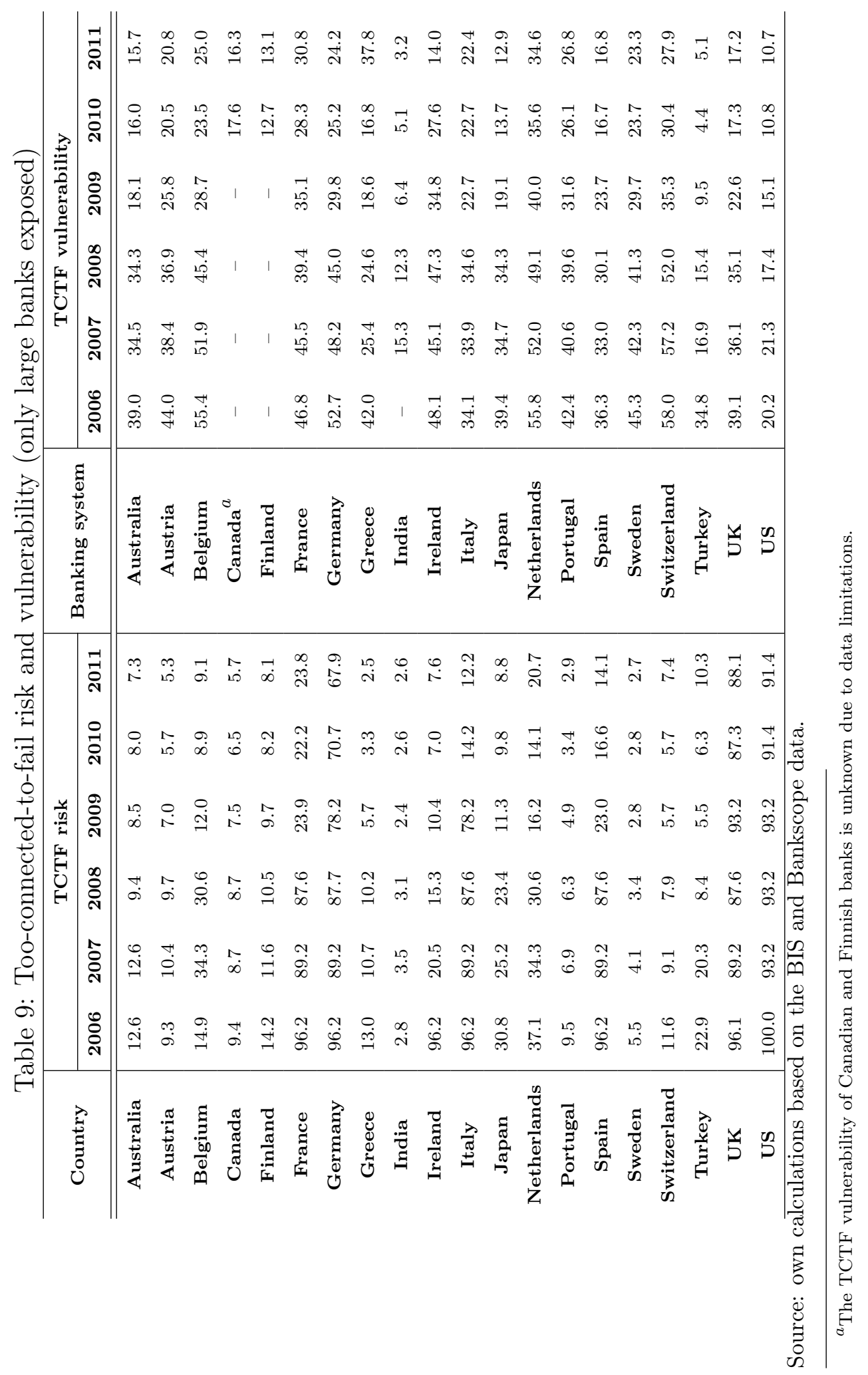



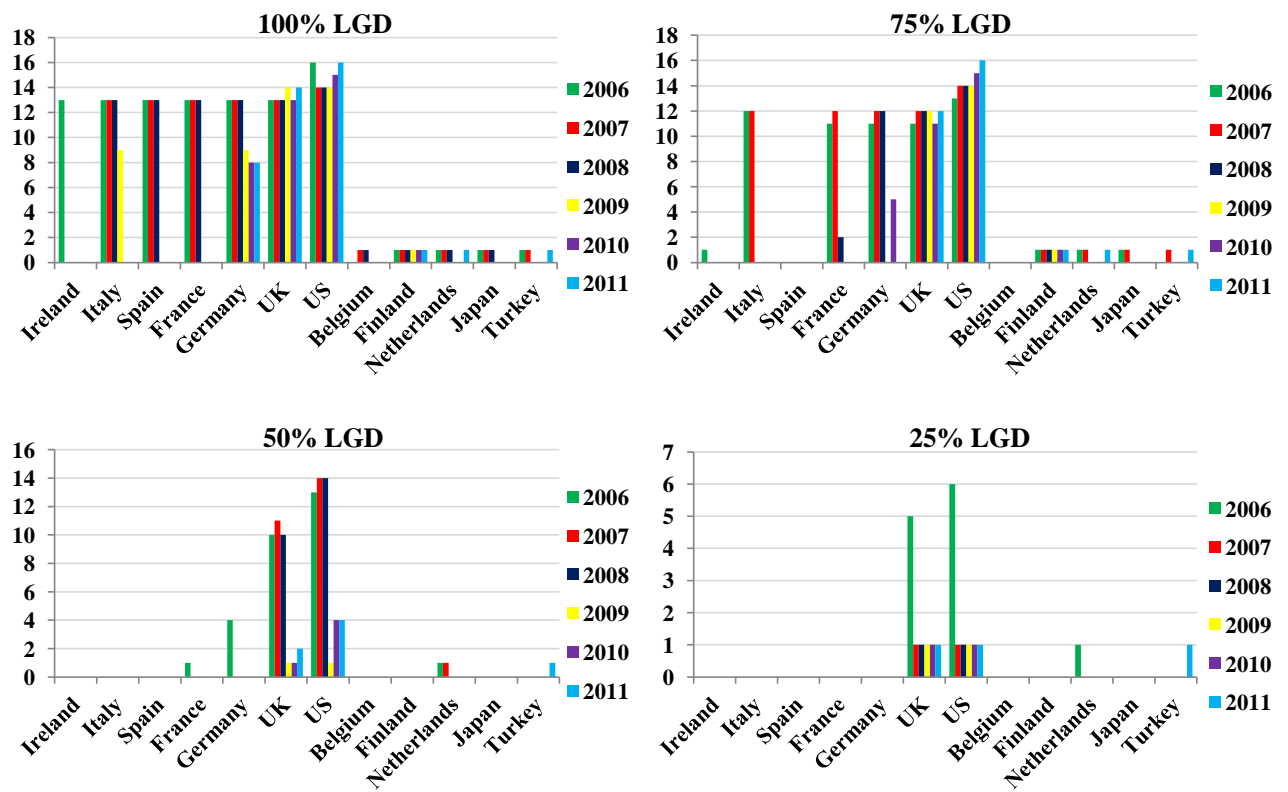

Figure 19: Number of induced failures by triggering countries (only large banks exposed)

Source: own elaboration based on Table 7 .

Table 10: Share of failed total capital excluding the trigger (100\% LGD, only large banks exposed)

\begin{tabular}{|c|c|c|c|c|c|c|}
\hline Country & 2006 & 2007 & 2008 & 2009 & 2010 & 2011 \\
\hline Australia & 11.2 & 12.5 & 8.9 & 8.7 & 8.5 & 8.2 \\
\hline Austria & 5.3 & 8.0 & 7.3 & 5.5 & 4.3 & 3.9 \\
\hline Belgium & 11.0 & 29.1 & 24.3 & 11.2 & 7.6 & 7.2 \\
\hline Canada & 8.4 & 8.6 & 7.6 & 7.4 & 6.8 & 6.6 \\
\hline Finland & 7.1 & 6.2 & 5.1 & 5.1 & 4.5 & 4.3 \\
\hline France & 84.4 & 90.0 & 84.6 & 22.4 & 20.0 & 18.5 \\
\hline Germany & 84.6 & 90.1 & 85.9 & 75.8 & 63.9 & 57.6 \\
\hline Greece & 6.1 & 5.9 & 5.7 & 3.8 & 2.2 & 1.5 \\
\hline India & 3.1 & 4.2 & 3.6 & 3.4 & 4.0 & 4.1 \\
\hline Ireland & 85.4 & 17.8 & 14.5 & 10.8 & 7.2 & 6.5 \\
\hline Italy & 84.8 & 90.3 & 85.5 & 77.0 & 14.2 & 11.8 \\
\hline Japan & 26.6 & 26.5 & 23.8 & 15.5 & 16.2 & 15.6 \\
\hline Netherlands & 27.0 & 27.7 & 23.5 & 13.0 & 11.9 & 13.5 \\
\hline Portugal & 5.6 & 5.3 & 4.9 & 4.4 & 3.2 & 2.7 \\
\hline Spain & 84.8 & 90.3 & 85.3 & 17.1 & 11.8 & 9.8 \\
\hline Sweden & 3.9 & 3.5 & 2.7 & 2.6 & 2.3 & 2.0 \\
\hline Switzerland & 8.4 & 7.7 & 6.4 & 5.9 & 5.1 & 5.4 \\
\hline Turkey & 8.6 & 8.9 & 2.7 & 2.2 & 2.4 & 4.0 \\
\hline UK & 82.5 & 89.1 & 83.9 & 98.8 & 89.3 & 88.7 \\
\hline US & 100.0 & 98.9 & 98.8 & 98.6 & 98.1 & 97.7 \\
\hline
\end{tabular}

Source: own calculations based on the BIS and Bankscope data. 

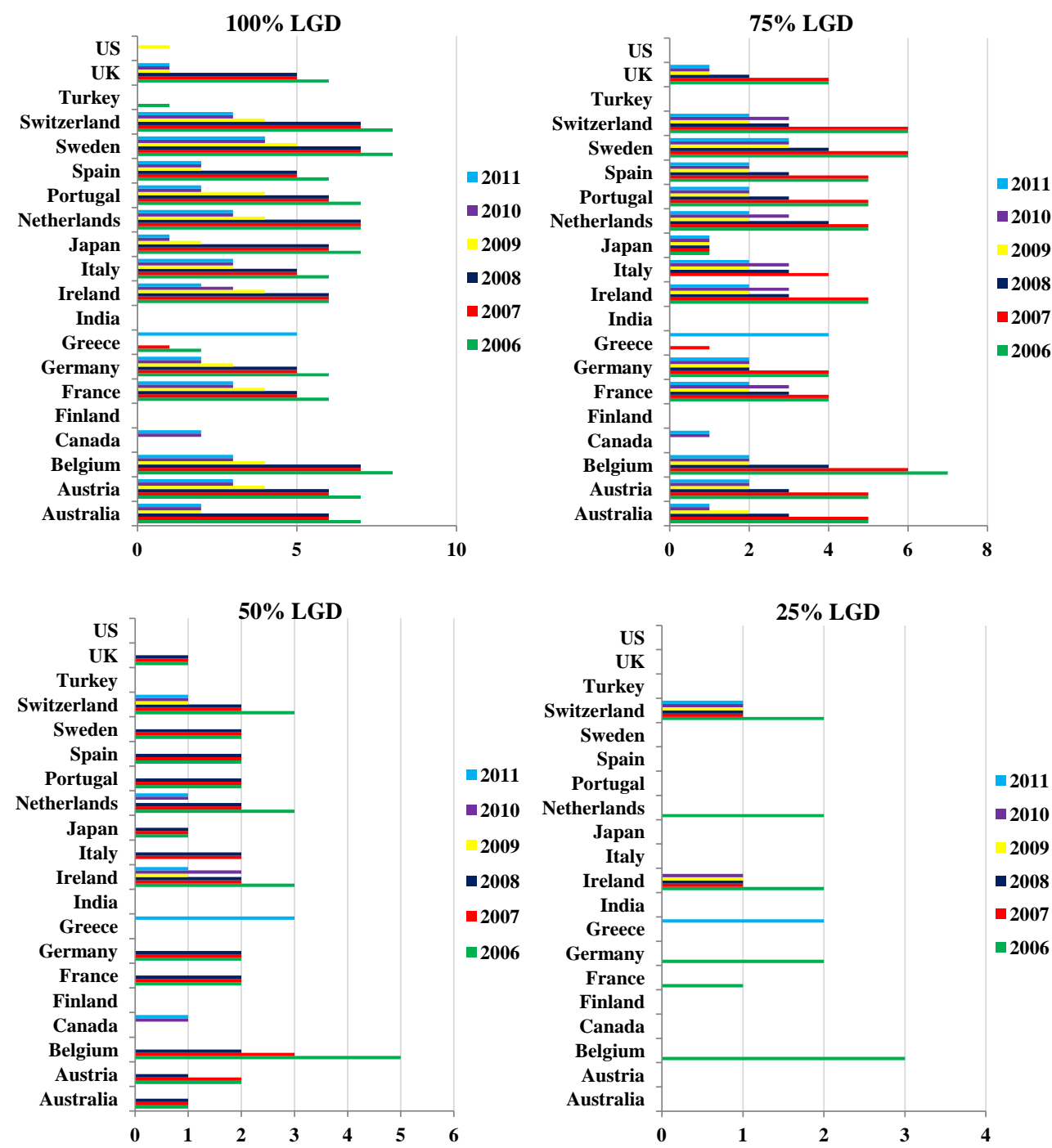

Figure 20: Vulnerability of countries (only large banks exposed) Source: own calculations based on the BIS and Bankscope data.
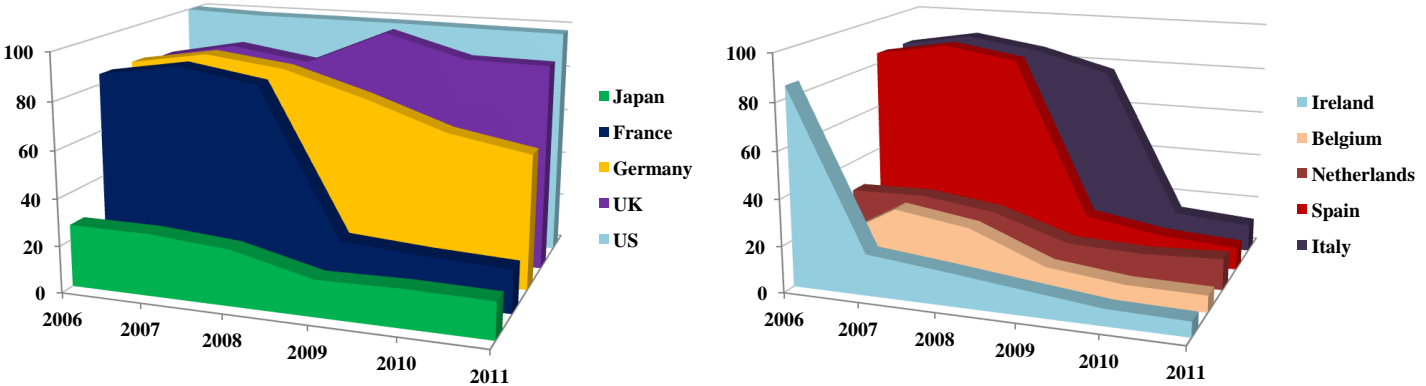

Figure 21: Share of failed total capital with 100\% LGD (only large banks exposed) Source: own elaboration based on Table 10. 


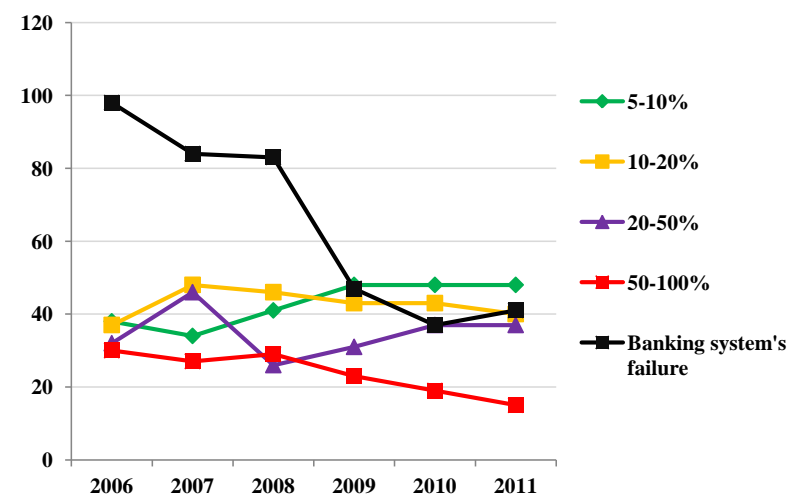

Figure 22: Number of banking systems grouped by the level of their capital losses with 100\% LGD (only large banks exposed)

Source: own calculations based on the BIS and Bankscope data. 


\section{References}

Acharya, V. V., Pedersen, L. H., Philippon, T., Richardson, M., 2010. Measuring systemic risk. Federal Reserve Bank of Cleveland, Working Paper 1002.

Allen, F., Babus, A., 2008. Networks in finance. Wharton Financial Institutions Center Working Paper 08-07.

Allen, F., Gale, D., 2000. Financial contagion. Journal of Political Economy 108 (1), $1-33$.

Babus, A., 2009. The Formation of financial networks. Discussion Paper 06-093, Tinbergen Institute.

Bisias, D., Flood, M., Lo, A. W., Valavanis, S., 2012. A survey of systemic risk analytics. Office of Financial Research Working Paper 0001.

Blundell-Wignall, A., Slovik, P., 2010. The EU stress test and sovereign debt exposures. OECD Working Papers on Finance, Insurance and Private Pensions 4.

Bolton, P., Jeanne, O., 2011. Sovereign default risk and bank fragility in financially integrated economies. NBER Working Paper Series 16899.

Boss, M., Elsinger, H., Summer, M., Thurner, S., 2003. An empirical analysis of the network structure of the Austrian interbank market. OeNB Financial Stability Report 7, 77-87.

Canedo, J., Jaramillo, S., 2009. A network model of systemic risk: stress testing the banking system. Intelligent Systems in Accounting, Finance and Management 16, $87-110$.

CGFS, 2011. The impact of sovereign credit risk on bank funding conditions. Committee on the Global Financial System Papers 43. 
Chan-Lau, J., 2010. Balance sheet network analysis of too-connected-to-fail risk in global and domestic banking systems. SSRN Electronic Journal.

Chin, S., 2013. Index to list of international bank mergers \& acquisitions. Available online at http://bankingmergers.blogspot.it/2010/01/index-to-list-of-internationalbank.html (last accessed 16 March, 2013).

Cihák, M., 2007. Introduction to applied stress testing. IMF Working Paper 59.

Cihák, M., Muñoz, S., Scuzzarella, R., 2011. The bright and the dark side of crossborder banking linkages. IMF Working Paper 186.

Degryse, H., Elahi, M., Penas, M., 2010. Cross-border exposures and financial contagion. International Review of Finance 10 (2), 209-240.

Degryse, H., Nguyen, G., 2007. Interbank exposures: an empirical examination of contagion risk in the Belgian banking system. International Journal of Central Banking 3 (2), 123-171.

Espinosa-Vega, M., Solé, J., 2010. Cross-border financial surveillance: a network perspective. IMF Working Paper 105.

Fungáčová, Z., Jakubík, P., 2012. Bank stress tests as an information device for emerging markets: the case of Russia. BOFIT Discussion Papers 3.

Furfine, C. H., 1999. Interbank exposures: quantifying the risk of contagion. BIS Working Papers 70.

Furfine, C. H., 2009. Interbank exposures: quantifying the risk of contagion. Journal of Money, Credit and Banking 35 (1), 111-128.

Gai, P., Kapadia, S., 2010. Contagion in financial networks. Proceedings of the Royal Society A 466, 2401-2423.

Garratt, R. J., Mahadeva, L., Svirydzenka, K., 2011. Mapping systemic risk in the international banking network. Bank of England Working Paper 413.

Hattori, M., Suda, Y., 2007. Developments in a cross-border bank exposure "network". Bank of Japan Working Paper Series 07-E-21.

International Monetary Fund, 2011. Mapping cross-border financial linkages: a supporting case for global financial safety nets. Strategy, Policy and Review Department. 
Iori, G., Jafarey, S., Padilla, F. G., 2006. Systemic risk on the interbank market. Journal of Economic Behavior \& Organization 61 (4), 525-542.

Krznar, M., 2009. Contagion risk in the Croatian banking system. Croatian National Bank.

Martinez-Jaramillo, S., Perez, O. P., Embriz, F. A., Dey, F. L. G., 2010. Systemic risk, financial contagion and financial fragility. Journal of Economic Dynamics \& Conrol 34, 2358-2374.

Mcguire, P., Tarashev, N., 2008. Global monitoring with the BIS international banking statistics. BIS Working Papers 244.

Memmel, C., Sachs, A., Stein, I., 2011. Contagion at the interbank market with stochastic LGD. Deutsche Bundesbank. Discussion Paper Series 2: Banking and Financial Studies 06/2011.

Minoiu, C., Reyes, J., 2011. A network analysis of global banking: 1978 - 2009. IMF Working Paper 74.

Mistrulli, P., May 2011. Assessing financial contagion in the interbank market: maximum entropy versus observed interbank lending patterns. Journal of Banking \& Finance 35, 1114-1127.

Müller, J., 2006. Interbank credit lines as a channel of contagion. Journal of Financial Services Research 29 (1), 37-60.

Nier, E., Yang, J., Yorulmazer, T., Alentorn, A., 2007. Network models and financial stability. Journal of Economic Dynamics \& Control 31, 2033-2060.

Rø rdam, K. B., Bech, M. L., 2009. The topology of Danish interbank money flows. Banks and Bank Systems 4 (4), 48-65.

Schoenmaker, D., Wagner, W., 2011. The impact of cross-border banking on financial stability. Duisenberg School of Finance - Tinbergen Institute Discussion Paper TI $11-05$

Takeyama, A., Constantinou, N., Vinogradov, D., 2011. Do CDS spreads reflect default risks? Evidence from UK bank bailouts. Available at SSRN: http://ssrn.com/abstract=1700167 or http://dx.doi.org/10.2139/ssrn.1700167. 
Toivanen, M., 2009. Financial interlinkages and risk of contagion in the Finnish interbank market. Bank of Finland Research Discussion Papers 6.

Upper, C., 2011. Simulation methods to assess the danger of contagion in interbank markets. Journal of Financial Stability 7 (3), 111-125.

van Lelyveld, I., Liedorp, F., 2006. Interbank contagion in the Dutch banking sector: a sensitivity analysis. International Journal of Central Banking 2 (2), 99-133.

von Peter, G., 2007. International banking centres: a network perspective. BIS Quarterly Review, December, 33-45.

von Peter, G., Upper, C., Wooldridge, P. D., 2006. Highlights of international banking and financial market activity. BIS Quarterly Review, September, 15-24.

Weistroffer, C., Möbert, J., 2010. Monitoring cross-border exposure. A primer on how to exploit the BIS banking statistics. Deutsche Bank Research, November.

Wells, S., 2004. Financial interlinkages in the United Kingdom's interbank market and the risk of contagion. Working Paper 230. 